\title{
NUEVAS REFLEXIONES SOBRE LA CONQUISTA Y PÉRDIDA CRISTIANA DEL ORIENTE DEL REINO DE GRANADA (1433-1447) A LA LUZ DE DOCUMENTOS DEL ARCHIVO DE LA CATEDRAL DE MURCIA ${ }^{1}$
}

\author{
NEW CONSIDERATIONS RELATED TO THE CHRISTIAN CONQUEST \\ AND LOSS OF EASTERN SECTOR OF THE KINGDOM OF GRANADA \\ (1433-1447) THANKS TO SOME DOCUMENTS OF MURCIA'S \\ CATHEDRAL ARCHIVE
}

Diego Antonio Reinaldos Miñarro

Universidad de Murcia

diegoantonio.reinaldos@um.es

RESUMEN: La conquista de las plazas granadinas de Xiquena y Tirieza en 1433 por las tropas del adelantado del Reino de Murcia, Alonso Yáñez Fajardo y del alcaide de Lorca, Martín Fernández Piñero, abrió el camino a un gran avance castellano por el sector oriental de la frontera del Reino de Granada (paralelo al desarrollado por la zona occidental) que, sin embargo, se vio interrumpido en la década de los cuarenta, cuando se perdieron casi todas las plazas ganadas, con excepción de las dos mencionadas. Durante esos años se llevó a cabo un intento de configuración institucional del territorio, en buena parte desde los vecinos Reino de Murcia y Obispado de Cartagena por un lado y Reino de Jaén y Arzobispado de Toledo por otro. El análisis de ese proceso y la reflexión sobre el mismo a la luz de documentos del Archivo de la Catedral de Murcia es el objetivo de este artículo.

PALABRAS ClAVE: Frontera de Granada, siglo XV, organización institucional, documentos.

1. Abreviaturas utilizadas: $\mathrm{ACM}=$ Archivo de la Catedral de Murcia; $\mathrm{AHN}=$ Archivo Histórico Nacional; $\mathrm{AMMu}=$ Archivo Municipal de Murcia; $\mathrm{AML}=$ Archivo Municipal de Lorca; CODOM = Colección de Documentos para la Historia del Reino de Murcia; AEM = Anuario de Estudios Medievales; $\mathrm{MMM}=$ Miscelánea Medieval Murciana; leg. = legajo; exp. = expediente

Este trabajo se inscribe en el seno de los siguientes proyectos de investigación: Proyecto de Excelencia El Milenio en sus documentos. Corpus diacrónico del español del Reino de Granada. 1492-1833 (CORDEREGRA). (P09-HUM-4466), financiado por la Consejería de Innovación, Ciencia y Empresa de la Junta de Andalucía (España) y los Fondos FEDER de la UE; y en el Proyecto de Investigación I+D+i Historia y videojuegos: el impacto de los nuevos medios de ocio y nuevas tecnologías sobre el conocimiento del pasado medieval (HAR2011-25548), financiado por el Ministerio de Economía y Competitividad del Gobierno de España. 
ABSTRACT: The conquest of Granada's fortresses of Xiquena and Tirieza in 1433 by the warlord of Murcia's kingdom Alonso Yáñez Fajardo and the governor of Lorca Martín Fernández Piñero was the beginning of a period of Castilian progress on the militar and institutional control in the Eastern sector of the Kingdom of Granada at the same time that some victories in the western took place. However, this progress was interrupted in the 1440s, when most of the fortresses were lost, except the two mentioned. During the Castilian control, an institutional configuration of territory was tested, thanks to the structures and population of the kingdoms of Murcia and Jaén, together with the bishopric of Cartagena and the archbishopric of Toledo. This article attempts to analyze the Castilian period using documents of Murcia's Cathedral Archive.

KEYWORDS: Frontier of Granada, $15^{\text {th }}$ century, institutional organization, documents.

\section{A Modo DE InTROducción: LA CONFIGURACiÓN DE LA Frontera de GranAda (siglos XIII-XV)}

El surgimiento del emirato nazarí de Granada fue el resultado de la consolidación del proceso de conquista y expansión castellana y aragonesa hacia el sur de la Península Ibérica iniciado ya en el siglo XII y culminado en vida de Fernando III y de su hijo, Alfonso X, por parte de Castilla, y de Jaime I por parte de Aragón. De hecho, la legitimación del nuevo emirato fue posible en buena medida gracias a la firma en 1246 del pacto de Jaén entre el rey castellano Fernando III y el primer monarca nazarí, Muhammad ben Yusuf ben Nasr al-Ahmar (el Rojo), antiguo caudillo sublevado en Arjona y que había establecido la capital de sus dominios en la ciudad del Darro y el Genil. Ese acuerdo, que permitía la supervivencia del que a la postre sería el único territorio dominado por una autoridad islámica desde 1250 hasta el final de la Edad Media, suponía la aceptación por ambas partes de un pacto de vasallaje inédito hasta el momento en la historia del Islam peninsular. A su vez, desde la perspectiva cristiana puramente feudal, se podía considerar que con ese vasallaje la Reconquista había terminado, ya que al fin y al cabo al-Ahmar no era más que un señor musulmán vasallo de un rey cristiano, al cual estaba obligado de prestar juramento de obediencia y fidelidad y de pagarle tributos anuales ( $p a$ rias) por el gobierno de sus dominios. Pero la realidad era mucho más compleja.

Lo cierto es que el nuevo reino, bajo la autoridad de los descendientes de Nasr, quedaría enmarcado entre las estribaciones del Sistema Bético y el Mar Mediterráneo y se consolidaría territorialmente en unos dominios que se corresponden aproximadamente con las actuales provincias de Almería, Granada y Málaga, más una pequeña porción de las de Cádiz y Jaén². Tanto la orografía, como las circunstancias exteriores y el proceso de legitimación llevado a cabo interna y ex

2. Véase mapa 1. 


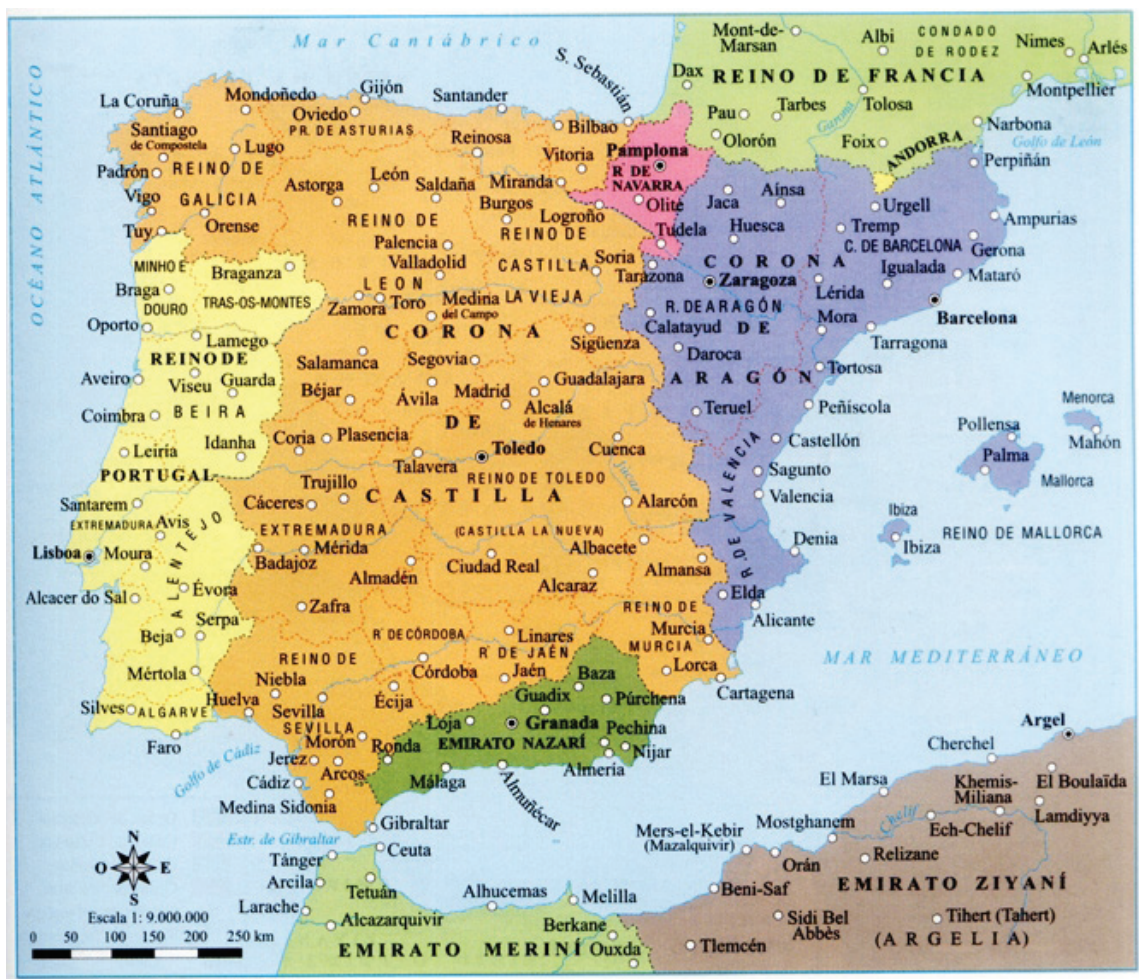

Mapa 1. La Península Ibérica a mediados del siglo XV. Fuente: López-Davalillo Darrea, Julio. Atlas histórico de España y Portugal. Desde el Paleolítico hasta el siglo XX, Madrid, Ed. Síntesis, 1999.

ternamente, entre otros factores, hicieron que el emirato sobreviviera durante más de doscientos cincuenta años, protagonizando una tercera parte de la historia de al-Andalus y dando lugar al surgimiento de la frontera entre Islam y Cristiandad más duradera de Europa occidental ${ }^{3}$.

3. El concepto de frontera ha generado y genera connotaciones muy paradójicas. Y para muestra, un botón, en una frase de Ortega recogida por Torres Fontes: vid. J. Torres Fontes. "Dualidad fronteriza: guerra y paz”, en P. Segura Artero (Coord.). Actas del Congreso la Frontera Oriental Nazarí como Sujeto Histórico (S.XIII-XVI): Lorca-Vera, 22 a 24 de noviembre de 1994, Almería, 1997, pp. 63-78, p. 65: "Decía Ortega y Gasset que la frontera tiene un signo irónico. Está destinada a separar dos mundos, pero el hecho es que quienes las habitan de uno y otro lado acaban por hacerse homogéneos". Así, la frontera ha de entenderse, más que como una línea divisoria, como un espacio controlado por un poder (en este caso la Corona de Castilla de una parte y el reino nazarí de Granada de otra) que acaba deviniendo en un espacio encastillado y en un área dinámica o sector que cambia dependiendo de la situación política y que termina siendo un espacio común de relaciones, más cercano al concepto anglosajón y norteamericano de frontier. Una temprana síntesis de la problemática la recoge el propio Torres Fontes en su obra Xiquena, castillo de la frontera, Murcia, 1979 ( $2^{\mathrm{a}}$ ed., reimp. 2007), pp. 13 y ss. De 
Dicha frontera quedó delimitada geográficamente en su parte occidental en las proximidades de la costa del Estrecho de Gibraltar, en torno a la desembocadura de los ríos Palmones y Guadarranque, tomando una dirección norte hasta llegar a las estribaciones de Sierra Margarita, donde giraría hacia el Este. Por esa zona, se mantenía en torno a una línea imaginaria de fortalezas en manos granadinas (Zahara, Setenil, Ardales) y cristianas (Olvera, Pruna, Teba...). A la altura del cauce del Guadalteba y del río Yeguas, la frontera adoptaba una dirección noreste, adentrándose hasta 1410 por tierras de Ronda y de los llanos de Antequera hasta el Genil, penetrando en su zona central, donde destacaban plazas como Benamejí, Rute, Priego, Locubín y Alcalá la Real, pasando a manos castellanas las sierras de Halconera y Albayate a mediados del siglo XIV. Hacia el Este, la frontera se dirigía hacia las zonas jienenses, posiblemente por el río Guadalbullón hasta Sierra Mágina, destacando las plazas de Torres, Jódar, Bélmez y Cabra del Santo Cristo en poder castellano y Huelma, Solera y Cambil en poder de los granadinos. Finalmente, la frontera giraba hacia el Noreste, paralela a las estribaciones de las sierras de Cazorla (donde se asentaba el adelantamiento del mismo nombre), Alcaraz y Segura (en manos de las órdenes militares de Santiago, el Temple y San Juan de Jerusalén y por donde lindaba con el arzobispado de Toledo), penetrando en el Reino de Murcia, del cual la separaba una zona de amplio vacío demográfico, para caer finalmente al Mediterráneo por los llamados Terreros Blancos, entre Águilas y Vera. Entre las plazas más representativas en el sector destacaban Castril, Huéscar, Baza y los Vélez por el norte y Vera hacia el sur, con Almería como gran puerto de abastecimiento, ya que la costa mediterránea se erigía en otra frontera marítima sometida a los vaivenes de la situación internacional, donde destacaba por encima del resto el puerto malagueño ${ }^{4}$.

Así las cosas, las variaciones territoriales producidas durante la Baja Edad Media fueron escasas (limitándose a las zonas occidental -con la incorporación de la zona del Estrecho, Gibraltar y Algeciras en el XIV y Antequera en 1410-, y central -con la anexión de Alcalá la Real y Alcaudete en la zona jienense), llegándose a hablar de una verdadera fijación y estabilización geográfica de la frontera, permaneciendo prácticamente inalterable desde mediados del siglo XIV hasta el inicio de la Guerra de Granada en 1482.

El nuevo espacio de contacto, como señalara Jiménez Alcázar, no se configuraba únicamente como el límite de la jurisdicción real, ni siquiera como un espacio exclusivamente militar, económico, cultural o religioso, sino como una

un momento posterior, centrado en el caso peculiar del reino nazarí de Granada, es de interés el trabajo de A. Bazzana. "El concepto de frontera en el Mediterráneo occidental en la Edad Media", en P. Segura Artero (Coord.). Actas del Congreso..., op. cit., pp. 25-46, en especial pp. 42-45. Recientemente, Juan Francisco Jiménez Alcázar, ha insistido en la definición fronteriza como instrumento de los nacientes Estados modernos en su proceso de formación. Vid. J.F. Jiménez Alcázar. "Gobernar fronteras: poderes locales, dominio territorial y control central en la Castilla meridional (ss. XIII-XVI)", Edad Media. Revista de Historia, 14 (2013), pp. 129-148, nota 1.

4. Sobre las delimitaciones geográficas de la frontera seguimos las líneas de M. García Fernández. "La frontera de Granada a mediados del siglo XIV", Revista de Estudios Andaluces, 9 (1985), pp. 69-86, pp. 70-72. 
mezcla de muchos factores que constituiría un referente de peligro, promoción social, intercambio económico y cultural, hipoteca hacendística, afirmación política e institucional y, a la larga, forja de recuerdo y memoria ${ }^{5}$. Así, y pese a lo que pudiera pensarse, la frontera distaba mucho de ser uniforme en lo que se refiere a la caracterización política, socioeconómica y cultural de los territorios que la circundaban, encontrándonos con muchos particularismos, si bien teniendo en cuenta una cierta uniformidad por la definición del propio hecho fronterizo.

No es nuestra intención aquí insistir sobre la articulación militar y estratégica del sistema defensivo, pivotado por el lado castellano en la existencia de concejos con grandes alfoces sostenidos a su vez desde la retaguardia (Lorca, Alcalá la Real, Écija, Estepa, Jerez) que se insertaban en el conjunto de entidades comarcales o regionales desde donde se controlaba el sector (los adelantamientos). En el lado granadino, por su parte, el territorio quedaba dividido en distritos de carácter fiscal, militar y judicial (iqlim y ta'as), a cuyo frente se situaban los cadíes, dependientes directamente del mayor de Granada por designación del emir o sultán, y encargados de representar su soberanía sobre el territorio, mientras que los caídes o alcaides poseían competencias militares sobre las distintas plazas fuertes de las demarcaciones, habiéndose implicado algunos también en funciones judiciales ${ }^{6}$. Un sistema de castillos con cierta entidad urbana, que los cristianos denominaron "villas de frontera" (Montefrío, Íllora, Colomera, Moclín, Iznalloz, Píñar, Benzalema, Tirieza hasta 1433, etc.) y de atalayas insertas en espacios de irrigación bastante poblados se situaban alrededor de grandes ciudades, enfrentadas estratégicamente a las posiciones del enemigo (Vera y Baza, con la avanzadilla de FilabresHuéscar-los Vélez frente a Lorca; Guadix y Granada frente a Jaén con Iznalloz y Alcalá la Real; Loja-Alhama y Ronda frente a Antequera y la Andalucía Bética) ${ }^{7}$.

Sí abundaremos más en los aspectos políticos, socioeconómicos y culturales que definían a estos espacios. Hay que señalar que éstos van a depender de la forma en que se llevaron a cabo los procesos de repoblación de dichos territorios en el XIII. Así, en el valle del Guadalquivir, la llamada Andalucía bética (sur de Cádiz, Sevilla, Córdoba, Jaén), la repoblación tuvo un marcado carácter militar, haciendo de la sociedad andaluza una sociedad organizada para la guerra donde amplias extensiones territoriales fueron entregadas por la Corona a miembros de la nobleza que se habían destacado en sus servicios militares durante los procesos de

5. Vid. J.F. Jiménez Alcázar. Op. Cit., p. 137.

6. Sobre los cadiazgos y alcaldías y su legitimidad, procedente de una delegación del soberano nazarí, vid. M. Arcas Campoy. "Cadíes y alcaides de la frontera oriental nazarí (s. XV)", al-Qantara, XX-2 (1999), pp. 487-501 y A. Peláez Rovira. El emirato nazarí de Granada en el siglo XV. Dinámica política y fundamentos sociales de un Estado andalusí. Granada, 2009, pp. 122-138.

7. Sobre las llamadas villas de frontera, vid. A. Malpica Cuello. "Las fortificaciones de la frontera nazarí-castellana, PH. Boletín del Instituto Andaluz del Patrimonio Histórico, año 9, 36 (2001), pp. 216-224 y del mismo autor, "Un asentamiento fortificado en la frontera nazarí-castellana: Castril de la Peña”, Studia historica. Historia medieval, 24 (2006), pp. 197-225. Sobre el agroecosistema irrigado que daba pie a una agricultura muy productiva, es interesante el artículo también de Malpica: Ídem. "El agua en la agricultura. Agroecosistema y ecosistemas en la economía rural andalusí", Vínculos de Historia, 1 (2012), pp. 31-44. 
conquista y a las grandes casas nobiliarias (como la de Medina Sidonia). Se configuraba así un territorio señorializado en un proceso que tiene muchas similitudes al que se llevaría a cabo dos siglos más tarde en el Reino de Granada, pero con unas connotaciones diferentes ${ }^{8}$, y con un desarrollo económico basado en la ganadería y la agricultura en grandes propiedades latifundistas, y en el contrabando y el saqueo. En el lado murciano, por el contrario, fue escasa la entrega de grandes extensiones territoriales a la nobleza y, la Corona, consciente de los problemas a solucionar, trató desde el primer momento de dirigir un proceso repoblador que girara en torno a los grandes concejos de realengo (Murcia, Lorca, Cartagena, Mula, Orihuela y Alicante hasta el XIV), con participación de las órdenes militares en las zonas del Noroeste. Su fracaso fue manifiesto, debido a la falta de pobladores castellanos y la gran presencia de pobladores catalanoaragoneses y a la permanencia de la población mudéjar, junto con la condición de territorio fronterizo, las intervenciones aragonesas y la dinámica posterior. El resultado fue un espectro social diferente al andaluz, sin el predominio de casas nobiliarias de importancia, sino de linajes de segundones o de caudillos fronterizos como los Manuel o los Fajardo ya a partir del siglo XIV ${ }^{9}$. Económicamente, grandes extensiones territoriales quedaron vacías de población y la subsistencia se fundamentó esencialmente en la ganadería, la apicultura, el contrabando y la obtención de botín. Tanto en unas zonas como en otras se produjeron procesos de asimilación cultural y se dieron momentos no sólo de tensión, sino también de convivencia, intercambio y resolución de conflictos a nivel local (la costumbre determinó la existencia de una jurisprudencia fronteriza) $)^{10}$.

8. El proceso andaluz de conquista y repoblación tiene su referente de estudio en la figura señera de Manuel González Jiménez, cuya prolija bibliografía sería imposible mencionar aquí. Señalaremos únicamente dos aportaciones recientes: M. González Jiménez. "La conquista y formación de Andalucía”, en M. González Jiménez y J.E. López de Coca Castañer (dirs.). Historia de Andalucia, t. IV, Barcelona, 2006, pp. 12-47. Centrada en el reino sevillano: M. González Jiménez. La Repoblación del Reino de Sevilla en el siglo XIII, Granada, 2008. Sobre el desarrollo del proceso de asentamiento nobiliario, puede verse el artículo de J.Ma Alcántara Valle. "Nobleza y señoríos en el reino de Granada durante el reinado de Alfonso X. Aproximación a su estudio", Vinculos de historia, 2 (2013), pp. 207-232.

9. El proceso de conquista y repoblación del Reino de Murcia lo sintetizó en su día muy bien su principal estudioso, el profesor J. Torres Fontes, quien le dedicó varios libros y editó la mayoría de los repartimientos (Murcia en 1960; con ed. facsímil en 1991; Orihuela en 1988 con facsímil en 2010; Lorca en 1977 con reedición actualizada en 1994). La síntesis para 1991 en J. Torres Fontes. "Reconquista y repoblación del Reino de Murcia", Actas del Coloquio de la V Asmblea General de la Sociedad Española de Estudios Medievales, Zaragoza, 1991, pp. 249-272. Recientemente le ha dedicado unas líneas en su manual Á.L. Molina Molina. Murcia medieval (siglos VIII-XV), Murcia, 2014, pp. 33-45. El proceso desde el punto de vista de la intervención aragonesa fue analizado, entre otros, por $\mathrm{M}^{\mathrm{a}} \mathrm{T}$. Ferrer i Mallol. La frontera amb l'Islam en el segle XIV. Cristians i sarraïns al País Valencià, Barcelona, CSIC, 1988 y Organització i defensa d'un territorio fronterer. La Governació d'Oriola en el segle XIV, Barcelona, CSIC, 1990; y por J.Mª del Estal. El Reino de Murcia bajo Aragón, Alicante, 1985, 1990 y 1999.

10. Sobre el carácter de la frontera como espacio de convivencia e intercambio ha insistido mucho el profesor José Rodríguez Molina en algunas de sus aportaciones. $V$. gr. J. Rodríguez Molina. "La frontera de Granada, siglos XIII-XV", en I Jornadas de Estudios de Frontera. Alcalá la Real y el Arcipreste de Hita, Jaén, 1997, pp. 503-560, donde documentó, entre otros aspectos, la existencia de espacios de aprovechamiento común de pastos en la zona jienense, los llamados "entredichos", 
La conformación de esta nueva realidad fronteriza había significado la ruptura de comarcas uniformes que hasta entonces habían constituido un mismo espacio político, socioeconómico y cultural, como es el caso del Campo de Gibraltar, del Valle del Guadalquivir o del corredor levantino entre Murcia y Almería, si bien como hemos visto la ruptura no fue total. No obstante, por todo lo que hemos señalado, se hace necesario tener muy presente el fenómeno frontera a la hora de analizar los sucesos acaecidos en el periodo 1433-1447, auténtico prólogo de la verdadera configuración institucional y territorial establecida después de 1492. El hecho fronterizo condicionaría en buena medida la forma en la que se llevaron a cabo los intentos de control sobre el territorio oriental nazarí en época de Juan II, donde el conocimiento del otro lado ${ }^{11}$ y del otro $^{12}$ se constituía en un aspecto fundamental, en tanto en cuanto los fronteros (los que vivían en, de y para la frontera) y los repobladores se adentrarían o asentarían en una u otra zona en función de esos conocimientos y arrastrando un acervo cultural determinado.

Las razones por las cuales en estos años el dominio sobre los territorios mencionados no cuajó son variadas. El objetivo de las siguientes líneas no es tanto un nuevo análisis del proceso, sino el de aportar nuevos documentos referentes al periodo procedentes del Archivo de la Catedral de Murcia y realizar algunas reflexiones al respecto sobre cuáles eran los derroteros que seguían los acontecimientos en un ámbito cronológico que ceñimos a las décadas de 1430 y 1440 y en un ámbito espacial centrado en la zona oriental granadina, lo que no nos impide tener una perspectiva comparativa (tan necesaria en Historia) con otras zonas de la frontera y una perspectiva diacrónica, aludiendo a momentos anteriores o posteriores.

\section{BALANCE HISTORIOGRÁFICO SOBRE LA FRONTERA MURCIANO-GRANADINA EN TIEMPOS DE JUAN II}

Son escasos hasta el momento los estudios acerca de la frontera murciano-granadina, si exceptuamos los trabajos, ya clásicos, pero no por ello menos válidos,

también documentados en la zona malagueña. Sobre el papel de los poderes locales en la resolución de conflictos, en la representación del poder central y en el desarrollo de la jurisprudencia fronteriza pueden verse las aportaciones de J.F. Jiménez Alcázar. "Relaciones interterritoriales en el Sureste de la Península Ibérica durante la Baja Edad Media: cartas, mensajeros y ciudades en la frontera de Granada", Anuario de Estudios Medievales (AEM), 40/2, (2010), pp. 565-602 y la mía propia: D.A. Reinaldos Miñarro. "A frontier cartulary. The Lorca's council (Murcia, Spain) cartulary in the years 1463 and 1464 as a source to study the frontier relationships between Murcia and Granada's Kingdoms", The Urban late Medieval Society. Actas del II IMM Lleida 2012, Turnhout (en prensa).

11. A este respecto es de interés el catálogo de la exposición celebrada en la ciudad de Lorca en 2009 , en el que tuve la ocasión de participar. Vid. VV.AA. El otro lado. Asentamientos rurales andalusies en la frontera oriental nazarí, Murcia, 2009.

12. M. García Fernández. "Sobre la alteridad en la frontera de Granada. Una aproximación al análisis de la guerra y la paz, siglos XIII-XV", Revista da Faculdade de Letras. História, III Serie, 6 (2005), pp. 213-235. 
del profesor Torres Fontes. La mayoría de ellos, publicados en diversas revistas de ámbito local, regional o nacional a lo largo de una larga y dilatada carrera investigadora, fueron recogidos en dos volúmenes recopilatorios titulados La frontera murciano-granadina (2003) e Instituciones y sociedad en la frontera murcianogranadina (2004), que vieron la luz en una edición coordinada por la Real Academia Alfonso X el Sabio de Murcia ${ }^{13}$.

En estas contribuciones, Torres Fontes analizaba el reflejo de los asuntos granadinos en el solar murciano, fundamentalmente a través de las actas capitulares y registros de cartas del Archivo Municipal de Murcia, cotejando los datos con la información de las crónicas del reinado de Juan II, esencialmente la de Fernán Pérez de Guzmán y la del Halconero.

También había tratado el tema en su obra Xiquena, castillo de la frontera (1960), donde plasmaría de forma sintética y narrativa los sucesos acaecidos en el ámbito de la frontera entre Castilla y Granada en general y entre el Reino de Murcia y el nazarí de Granada en particular durante los años que van desde 1432 hasta la conquista de $1492^{14}$.

Reflexiones y alusiones directas o indirectas a las relaciones entre los reinos de Murcia y Granada las encontramos en otras de sus obras, como las dedicadas a los dos primos del clan Fajardo que se disputaron el poder en el reino murciano durante gran parte del siglo XV, Alonso y Pedro, sin menospreciar otros artículos o colaboraciones en obras colectivas que sería imposible mencionar aquí por razones de espacio ${ }^{15}$.

El testigo del Dr. Torres Fontes lo han cogido muchos de sus discípulos, que se han dedicado a analizar diversas facetas de la frontera. Para el periodo y tema que nos atañe, son de destacar las aportaciones de Francisco de Asís Veas Arteseros y Juan Francisco Jiménez Alcázar. Del primero resultan especialmente interesantes las centradas en el papel del obispado de Cartagena y de la ciudad de Lorca en la zona oriental granadina ${ }^{16}$, y del segundo aquellas en las que ha estudiado las vías en las que la Corona imponía su dominio territorial sobre la frontera, las relaciones

13. J. Torres Fontes. La frontera murciano-granadina, Murcia, 2003 e Instituciones y sociedad en la frontera murciano-granadina, Murcia, 2004.

14. J. Torres Fontes. Xiquena, castillo de la frontera, Murcia, $1^{\mathrm{a}}$ ed. 1960 (2 $2^{\mathrm{a}}$ ed., 1979 y reimp. en 2007).

15. J. Torres Fontes. Fajardo el Bravo, Murcia, $1^{\mathrm{a}}$ ed., 1944 ( $2^{\mathrm{a}}$ ed. Real Academia Alfonso X El Sabio, 1994 y $3^{\text {a }}$ de 2001) y Don Pedro Fajardo, Adelantado Mayor del Reino de Murcia, Madrid, 1953. Remitimos para el resto de obras a los diversos repertorios biobliográficos que existen sobre la figura de don Juan. Cfr. M. Martínez Martínez. "La obra del medievalista murciano Juan Torres Fontes", en Homenaje al Profesor Juan Torres Fontes, vol. II, Murcia, 1987, pp. 1017-1030; M.A. Jover Carrión. Juan Torres Fontes y el Archivo Municipal, Murcia, Ayuntamiento de Murcia, 1988; Á.L. Molina Molina. "Juan Torres Fontes. (Notas para su biobibliografía)", Revista Electrónica de Estudios Filológicos, 15 (2008), en línea. La semblanza más reciente sobre su figura y aportaciones fue realizada por F. de A. Veas Arteseros. "In memoriam. Prof. D. Juan Torres Fontes (1919-2013)", Anuario de Estudios Medievales, 43/2 (julio-diciembre de 2013), pp. 943-948.

16. F. Veas Arteseros. "Lorca, base militar murciana frente a Granada en el reinado de Juan II (1406-1454)", Miscelánea Medieval Murciana, 5 (1980), pp. 159-188 y "El Obispado de Cartagena. Una frontera político-religiosa", Murgetana, 114 (2006), pp. 19-51. 
entre uno y otro lado a través de personajes e instituciones fronterizas o la configuración del espacio fronterizo a partir de la sociedad que lo habita y define ${ }^{17}$.

De todas las contribuciones mencionadas se obtiene la visión de una frontera murciano-granadina geográficamente estable hasta el periodo que analizamos, cuando se producen modificaciones significativas. Dicha frontera en estos momentos se caracterizaba por su longitud (abarcando desde el Mediterráneo entre Vera y Águilas hasta la encomienda santiaguista de Letur a lo largo de 140 kilómetros) y por su profundidad (con amplios despoblados). Ahora bien, existían aspectos diferenciales a ambos lados.

En el lado granadino, encontramos una primera línea de castillos avanzados (zona de los Vélez hacia el Sur) a la que seguía una segunda línea, desde Huéscar y por todo el valle del Almanzora hasta Vera, con una densidad de población muy importante dedicada al cultivo de ricas huertas que abastecían a las fortalezas y a la población. Cultivos que resultaban muy dañados en las talas y saqueos efectuados en las incursiones realizadas desde territorio cristiano que lograban penetrar hacia el interior.

El contraste se producía en el lado murciano, donde nos encontramos con una línea de vanguardia de fortalezas dependientes de una fortaleza base con gran capacidad defensiva y de acoger efectivos suficientes como para socorrer de urgencia a las demandas de ayuda, además de proteger hombres y ganados en caso de necesidad. En el adelantamiento murciano este papel lo jugaba Lorca, de realengo, junto con Caravaca y Segura, de la orden santiaguista. En la villa lorquina (ciudad desde 1442 por privilegio de Juan II), es donde se encontraba la jefatura del sector y donde se centraban las tropas reales cuando el adelantado asumía la jefatura de las mismas, siendo Murcia la ciudad que sostenía el entramado desde la retaguardia. Entre unas fortalezas y otras se abrían grandes extensiones territoriales despobladas, yermas e incultas, zonas de paso o lugares donde sólo era posible el pastoreo o la apicultura. Vemos pues, cómo desde el punto de vista socioeconómico, diversos factores como la inseguridad habían modificado las características de un territorio antes uniforme, sometido desde mediados del XIII a un profundo proceso de despoblación.

En cualquier caso, en la frontera existían instituciones y personajes fronterizos, surgidos de las necesidades comunes a uno y otro lado, desde las puramente defensivas y militares (adelantados, caudillos, adalides...), hasta las más cotidianas (interpretación lingüística, relaciones comerciales, contrabando...), pasando por el rescate de cautivos cuando era necesario a causa de las acciones depredatorias de ambos bandos (ejeas o alfaqueques, cofradías y órdenes de cautivos...). Así, cuando se producía algún conflicto o había que determinar alguna necesidad o tratar alguna cuestión, se acudía a la jurisprudencia fronteriza, que venía deter-

17. J.F. Jiménez Alcázar. "Relaciones interterritoriales...", Op. cit., pp. 565-602; "Et por estar esta tierra en frontera de moros: sociedad y territorio en la frontera de Granada (siglos XIV-XV)", en J.I. de la Iglesia Duarte (Coord.). Monasterios, espacio y sociedad en la España cristiana medieval: XX Semana de Estudios Medievales. Nájera, del 3 al 7 de agosto de 2009, Logroño, 2010, pp. 353-394; y "Gobernar fronteras...", op. cit. 
minada por un derecho consuetudinario, no escrito, donde las instituciones de las zonas más cercanas a la frontera (léase concejos y guardas de fortalezas) tenían mucho que decir, con un papel que se materializaba incluso en la adopción de treguas locales ${ }^{18}$.

\section{LA OFENSIVA CRISTIANA DE 1433-1439}

La década de los treinta del siglo XV vería uno de los mayores cambios en la frontera castellano-nazarí desde las conquistas de Gibraltar y Antequera en las dos primeras décadas de la centuria. Así, una guerra de desgaste mediante la acción combinada de nobles y aristócratas oriundos o desplazados a los diferentes reinos, obispados o adelantamientos desde donde se ejercía la autoridad militar en la frontera, al mando de tropas pagadas por el rey, posibilitó la pérdida de una importante extensión territorial por parte del poder nazarí; territorios que en la década siguiente volverían en su mayor parte a manos musulmanas. De esta forma, en la zona occidental encontraremos al conde de Niebla, don Enrique de Guzmán; al maestre de Alcántara, Gutierre de Sotomayor, y al adelantado mayor de Andalucía, Diego de Ribera; mientras que en la zona central veremos moverse a don Fernando Álvarez de Toledo, fundador de la Casa de Alba, señor de Valdecorneja y capitán mayor de la frontera de Córdoba y Jaén ${ }^{19}$; al adelantado de Cazorla, Rodrigo de Perea, y al comendador de Segura, don Rodrigo Manrique. El adelantado del Reino de Murcia, don Alonso Yáñez Fajardo, junto con los contingentes de las órdenes militares, aglutinarían el mando por la zona oriental.

Pero el proceso, analizado en su conjunto, fue fruto de una combinación de factores, entre los que se contaban, no sólo la acción unificada (o a veces individualizada como veremos) de varios de los personajes mencionados, sino también de las discordias en el seno del reino granadino y de la paralización de la guerra de Castilla con Aragón tras las treguas de Majano de 1430. Todo ello permitió a don Álvaro de Luna afianzar su posición para una acción militar contra Granada, llevada a cabo a inicios de julio del año siguiente, cuando Juan II se enfrentó a los musulmanes cerca de Atarfe, en la célebre batalla conocida como de la Higueruela, donde las tropas dirigidas por el sobrino del sultán Muhammad IX, el futuro Yusuf V "el Cojo", sufrían una severa derrota ${ }^{20}$. Sin embargo, las diferencias posteriores en la Corte castellana llevaron consigo un cierto abandono de la frontera

18. Un ejemplo puede ser la concertada entre Lorca y Caravaca con el caudillo Abendega de Baza, que incluía toda la hoya de Baza desde Zújar hasta Mojácar, cuya renovación consideraba necesaria el concejo lorquino en carta a Caravaca del 10 de julio de 1464. Cfr. AML, Cartulario 1463-1464, fol. $63 \mathrm{v}$.

19. Al personaje le dedicó un artículo de gran interés, en el que se estudiaban los acontecimientos fronterizos de esos años a la luz de documentos del Archivo Ducal de Frías y se corregían y matizaban algunos estudios anteriores, el profesor J.E. López de Coca Castañer. "Fernando Álvarez de Toledo, capitán de la frontera de Jaén (1434-1437)", AEM, 33/2 (2003), pp. 643-666.

20. Así lo cree Roser Salicrú, quien reformuló el listado de los reyes granadinos. Vid. R. Salicrú i Lluch. El sultanat de Granada i la Corona d'Aragó, 1410-1458, Barcelona, 1998, p. 291, nota 132. 
que fue aprovechado por las fuerzas de Muhammad IX para ocupar Cambil y Bélmez hacia 1432 y destruir parte de Algeciras.

La reacción cristiana no se hizo esperar y al año siguiente, Fernando Álvarez de Toledo, capitán mayor de la frontera de Córdoba y Jaén, se hacía con Benzalema.

En la frontera oriental el avance se inició hacia los primeros días del otoño de 1433, ya que las noticias a Murcia llegaron el 3 de octubre, recompensándose al mensajero:

Otrosy ordenaron e mandaron que sean reçebidos en cuenta al dicho mayordomo los çient maravedis de dos blancas el maravedí que dio por mandado del dicho conçejo a Antón de Seuilla de albriçias por las nueuas que troxo de cómo el sennor adelantado auía ganado los castillos de Xiquena e Tirieça de poder de los enemigos ${ }^{21}$.

El hecho a que el mensajero hacía referencia debió suceder días antes, cuando una hueste dirigida por el adelantado del Reino de Murcia, Alonso Yáñez Fajardo II, y con la participación de tropas lorquinas con su alcaide Martín Fernández Piñero a la cabeza, se adentraron por el valle del Guadalentín con el propósito de conquistar las plazas nazaríes de Xiquena y Tirieza. Probablemente las dificultades orográficas determinaran el uso de una lombarda fabricada en Lorca que reventó en sus primeros disparos, matando a uno de los encargados de su manejo, pero que ayudó a la caída del castillo de Xiquena, a cuyas puertas precisamente el adelantado armó caballero a su sobrino, Alonso Fajardo, un personaje llamado a protagonizar las siguientes décadas del siglo XV murciano, prototipo de fronterizo indisciplinado, querido por unos, que lo llamaron "el Bravo", y odiado por otros, que lo denominaron "el Malo", pero respetado y temido a uno y otro lado de la frontera murciano-granadina ${ }^{22}$.

Merece la pena detenerse en estas conquistas, ya que su situación estratégica como avanzadilla hacia los Vélez favorecería otras posteriores y a la postre serían las dos únicas plazas orientales que se mantendrían en poder castellano tras la pérdida durante el bienio 1445-1447 de todo lo que se había conquistado en los años treinta. Durante la década de 1450, Xiquena y Tirieza permanecerían en poder de Alonso Fajardo, hasta que éste, caído ya en desgracia, las vendió a don Juan Pacheco, marqués de Villena, en $1459^{23}$. Don Juan (y luego su hijo don Diego) accedía así al control de las aguas del río Vélez y del nacimiento de Tirieza, y se hacía con unas posiciones fundamentales para sus planes expansivos hacia el Reino de Granada e incluso hacia la ciudad de Lorca ${ }^{24}$; sirviéndole además de

21. AMMu, Actas Capitulares, $n^{\circ}$ 56, sesión 03-X-1433, f. 17v.

22. Para conocer más detalles sobre el personaje sigue constituyendo una referencia la obra de J. Torres Fontes. Fajardo el Bravo, Murcia, 1944.

23. La carta de venta, fechada en Caravaca, a 18 de agosto de dicho año, se conserva hoy en la Sección Nobleza del Archivo Histórico Nacional. AHN, Sección Nobleza, Frías, C. 120, D. 10-11.

24. En noviembre de 1463 el concejo de Lorca escribía al comendador Juan Fernández Galindo ante las pretensiones del marqués de Villena al ducado de Lorca (AML, Cartulario 1463-1464, n 29 , ff. $13 \mathrm{v}-14 \mathrm{r}$ ) y menos de un mes después, el 21 de diciembre, se dirigía al alcaide de Xiquena reafir- 
enriquecimiento mediante el mantenimiento de un juro de heredad de un millón de maravedíes para un proyecto de repoblación que no llevó a cabo, teniendo que concederse un privilegio de homicianos ${ }^{25}$.

En la frontera occidental y central también se sucedían los éxitos, pues el adelantado Gómez de Ribera se apoderaba a finales de año de Turón, Ardales e Iznájar y los habitantes de Íllora y Montefrío se sometían a la soberanía castellana ${ }^{26}$.

Poco después de los sucesos de Xiquena tuvo lugar una expedición murciana contra los Vélez en la cual murieron gran número de cristianos y fueron hechos otros muchos prisioneros, de lo que informaba Juan Marín, vecino de Lorca, a los miembros del concejo de Murcia, a quienes pedía ayuda para pagar los préstamos que le habían hecho para su rescate ${ }^{27}$. De desastrosas consecuencias fue también la expedición contra Vera que Torres Fontes fecha a principios de mayo de 1434, dirigida por Alonso Fajardo, hijo éste primogénito del adelantado, que murió luchando en una rambla cercana ante un número superior de fuerzas granadinas ${ }^{28}$. Precisamente su muerte le sería comunicada a don Alonso Yáñez Fajardo por un personaje cuya identidad se desconoce a través de una carta conservada en la Biblioteca Nacional y publicada en su día por Torres Fontes, que la consideró una de las mejores aportaciones al género epistolar del momento ${ }^{29}$. Crecidos los granadinos tras las derrotas cristianas, entraron en el Reino de Murcia por los campos de la encomienda santiaguista de Caravaca y atacaron Calasparra, incendiando sus arrabales y obteniendo gran botín pero, atrapados por la noche, se vieron obligados a pasarla en un campo cercano, mientras el comendador de Calasparra solicitaba ayuda a las poblaciones vecinas. Respondieron Caravaca y Lorca con presteza, la primera con fuerzas al mando del comendador Garci López de Cárdenas y Lorca con trescientos peones dirigidos por Martín Fernández Piñero, los cuales marcharon por Campo Coy para cortar la retirada a los musulmanes hacia Baza y se reunieron con los de Caravaca en el Puerto del Conejo -hoy Cañada de la Cruz-. Atacaron por sorpresa a los musulmanes y estos se vieron obligados a huir hacia Vélez Blanco sin oponer apenas resistencia. La presa obtenida fue considerable y provocó un exaltado pleito entre la villa de Lorca y los caballeros participantes ${ }^{30}$.

mando su pertenencia al realengo (AML, Cartulario 1463-1464, n” 30, f. 14r): "Que esta cibdat, Dios loado, es del sennor rey amada, e a ella sus cartas juradas por sus sennorias dada. E asi mesmo es de tal gente poblada que, avn lo que se dixese fuese asi, Dios e el rey e la buena gente $<$ que en ella es $>$ no lo consintiria, quanto mas que son aquestas cosas no creedoras".

25. Cfr. J.F. Jiménez Alcázar, J. Ortuño Molina. "El privilegio de repoblación de Xiquena (s. XV). Un proyecto frustado", Clavis, 4-5 (2008), pp. 33-51, p. 39.

26. Cfr. J.E. López de Coca Castañer. "Fernando Álvarez de Toledo...”, op. cit., p. 656.

27. AMMu, Actas Capitulares, $n^{\circ}$ 56, sesión 21-XI-1433, f. 26v.

28. J. Torres Fontes. "La muerte de Alonso Fajardo", en La frontera murciano-granadina, op. cit., pp. 204-205. Publicado originalmente en AEM, 4 (1967), pp. 409-418.

29. Ibid., pp. 209-212.

30. Recoge más detalles sobre la escaramuza J. Torres Fontes. Xiquena, castillo de la frontera..., op. cit., pp. 41-46. Un traslado de la carta de Juan II ordenando al concejo de Lorca pagarle a su abogado Pedro Carles el moro cautivo que le debían por haber logrado que el pleito le fuera favorable fue publicado por F. Veas Arteseros. "Lorca, base militar murciana frente a Granada...", art. cit., pp. 185-188. 
En la zona malagueña ocurría otro desastre paralelo al de Vera, cuando el adelantado de Andalucía, Diego de Ribera, al mando de las fuerzas sevillanas, intentaba hacerse en vano con Álora, encontrando la muerte en su valerosa acción. Dichos fracasos, no obstante, se contrarrestaban con los éxitos referidos en la zona oriental y con alguno más en la zona jienense, donde, tras algunas desgracias previas, las huestes concejiles de Úbeda, Baeza y Andújar que dirigía el comendador de Bedmar, don Fernando de Quesada, lograron hacerse con la fortaleza de Solera.

Pero sin duda alguna la hazaña más importante de 1434, que alcanzaría una enorme resonancia por su magnitud, llegando pronto a los oídos de Juan II, fue la conquista de Huéscar, que tuvo lugar el sábado 6 de noviembre a manos de don Rodrigo Manrique, comendador santiaguista de Segura y padre del famoso poeta Jorge Manrique. Su dominio suponía controlar una posición estratégica, capital de una vasta comarca que se extiende desde la Sagra hasta la hoya de Baza.

Según relataba el propio comendador a Juan II en una carta recogida en la Crónica del Halconero, la conquista de la plaza se produjo al asalto mediante escala, y fue el resultado de una organización basada en un conocimiento previo de la situación a través de parientes, adalides y escuderos, y de correrías de tanteo, desgaste y despiste para el enemigo. Junto con Rodrigo Manrique participaron en la acción Juan Enríquez, escalador, y los adalides Ruy Díaz, converso, Gonzalo García y Sancho González de Quesada. Acudieron también diversos caballeros con rocines y peones, entre los que se encontraban su tío Manuel de Benavides, Pedro de Quiñones, Gómez de Sotomayor, hijo del señor del Carpio; Gonzalo Fernández de Villalta, el comendador de Veas, el alcaide de Yeste; Gonzalo Díaz de Bustamante y Juan de Claramonte, venidos desde Alcaraz; Diego de la Cueva y Diego López de San Martín, venidos desde Úbeda junto con otros, y otros personajes procedentes del Campo de Montiel. Según el relato, la conquista fue posible gracias a un conjunto de acciones individuales y colectivas a las que no tardó en contestar el caudillo moro de Baza, conocido en las crónicas como el Cavezaní (Muhammad al-Qabsani), si bien pudo llegar a tiempo pese a las intensas lluvias la ayuda del adelantado de Cazorla, Rodrigo de Perea, y la del capitán mayor de la frontera de Jaén, Fernando Álvarez de Toledo, para defender el campo. Finalmente, los moros se avinieron a pactar la rendición y fueron echados de la fortaleza ${ }^{31}$. Volvía así Huéscar al poderío de la Orden de Santiago, a la que ya perteneciera en el siglo XIII, y Rodrigo Manrique, que quedaba como alcaide de la villa cristiana, era recompensado por Juan II con la merced de trescientos vasallos solariegos de la tierra de Alcaraz y con un juro de heredad de veinte mil maravedíes ${ }^{32}$.

31. Cfr. J. de M. Carriazo (ed.). Crónica del Halconero de Juan II, de Pedro Carrillo de Huete, Madrid, CSIC, 1946, pp. 164-174. Por su parte, la crónica de Fernán Pérez de Guzmán y Lorenzo Galíndez de Carvajal no es tan prolija en detalles: vid. F. Pérez de Guzmán, L. Galíndez de Carvajal. Crónica del señor Rey don Juan, segundo de este nombre en Castilla y en León, ed. Valencia, 1779, pp. 343-345.

32. J. de M. Carriazo (ed.). Crónica del Halconero..., op. cit., p. 223. F. Pérez de Guzmán, L. Galíndez de Carvajal. Crónica del señor Rey don Juan..., p. 345. Sobre los antecedentes de Huéscar en el dominio de la Orden de Santiago sigue siendo referencia el artículo de J. Torres Fontes. "Conquista 
Conquistada Huéscar, la plaza pasó a ser el bastión desde donde Manrique efectuaba incursiones por los territorios orientales nazaríes, como las realizadas hacia junio de 1435 por la zona del valle de Purchena y por tierras de Guadix (Fiñana y Abla), saltándose el seguro que su tío, el capitán general de la frontera, don Fernando Álvarez de Toledo, les había concedido (en política seguida con otras localidades), por lo que se disculpaba en carta desde Huéscar, a 25 de junio $^{33}$. Ese año lo fue también de intentos más o menos infructuosos de menoscabar al enemigo, tanto por parte del propio don Rodrigo, como por las acciones del jefe de los Fajardo murcianos por Baza y Guadix, o del señor de Valdecorneja y fundador de la Casa de Alba, que intentó apoderarse sin éxito de Huelma, mientras que en Alcalá la Real era apresado por los moros Alfonso de Estúñiga, cautivo de gran valor que no se recuperaría hasta la tregua de $1439^{34}$.

Precisamente fueron estos personajes los que protagonizaron el avance castellano de los años subsiguientes. Así, el adelantado de Murcia, Alonso Yáñez Fajardo, utilizaba la vía diplomática para rendir por capitulación las villas de Vélez Blanco y Vélez Rubio en enero de 1436. La importancia estratégica de las plazas era grande, sobre todo de Vélez Blanco, ya que, como señala la Crónica del Halconero, esta villa era llaue de toda aquella frontera de los moros, por lo que Juan II, que recibió la noticia en Alcalá de Henares, se holgó mucho de su conquista y les confirmó lo capitulado con el adelantado ${ }^{35}$. Ese mismo año, pero en la primavera, se entregaron, en este caso a Rodrigo Manrique, Galera y Castilléjar, y en mayo capitulaba Benamaurel ante Álvarez de Toledo ${ }^{36}$. Según Torres Fontes, es probable que Orce se incorporara a manos del adelantado de Murcia por el mismo momento que Galera y Castilléjar, y lo cierto es que es una de las plazas que aparece en la tregua castellano-granadina de 1439 y que, junto con los dos Vélez, pasaría a formar parte del señorío que Juan II le concedería al adelantado Yáñez Fajardo en diciembre de ese año ${ }^{37}$.

Las ganancias de dominios por parte de Castilla podrían haber sido mayores si la diplomacia castellana hubiese sabido aprovechar la oportunidad que suponía la oferta que Juan II recibió estando en Alcalá de Henares en 1436 por parte de una embajada de delegados de las ciudades de Baza y Guadix. Solicitaban al monarca que eligiera un reyezuelo musulmán para ellos (probablemente Abenamalit) y lucharían contra Muhammad IX "el Zurdo”, pero la reacción de Juan II, ocupado en las negociaciones de un tratado con Aragón y Navarra, fue la de retrasar la

y pérdida de Huéscar en el reinado de Juan II de Castilla", en Instituciones y sociedad..., op. cit., pp. 435-462, en especial pp. 450-451. Publicado originalmente en Murgetana, 84 (1992), pp. 81-99.

33. C $f r$. A. Torreblanca López. "Una expedición de Rodrigo Manrique contra la frontera de Granada (junio de 1435)", en VV. AA. Homenaje al profesor Juan Torres Fontes, Murcia, 1987, pp. 1673-1680.

34. Cfr. J. E. López de Coca Castañer. "Fernando Álvarez de Toledo...", op. cit., pp. 649-651.

35. J. de M. Carriazo (ed.). Crónica del Halconero de Juan II..., op. cit., pp. 224-225.

36. Ibid., pp. 227-228.

37. Vid. J. Torres Fontes. "Alonso Yáñez Fajardo y su señorío de Vélez Rubio, Vélez Blanco y Orce", en Instituciones y sociedad en la frontera murciano-granadina, op. cit., pp. 417-433, p. 426. Publicado originalmente en Scripta. Estudios en homenaje a Élida Garcia Garcia, Oviedo, 1998, pp. 603-610. 
respuesta para luego pedir la entrega previa de las fortalezas y el vasallaje o que continuaría la guerra, por lo que los delegados se volvieron enfadados al reino granadino $^{38}$. Fue, sin duda, una ocasión perdida de menoscabar aún más el poder nazarí, aumentando la intervención en las discordias internas y propiciando un clima de desprotección entre la población granadina, gracias al cual se había producido la entrega anterior de muchas otras fortalezas, pudiendo quizá ser mayor ahora el avance territorial.

Pese a todo, el mismo año de 1436, a principios del otoño, se produjo la toma de Albox, una fortaleza importante en el sector sur de la frontera oriental. La acción se produjo a la escala por parte de Pedro Fajardo, sobrino del adelantado Alonso Yáñez Fajardo, de lo cual daba cuenta en 17 de octubre una carta de Lorca al concejo de Murcia, desde donde se movilizaron caballeros y peones para reforzar la posición. También debieron pasar bajo la tutela castellana por esos momentos Cantoria y Arboleas, ya que Torres Fontes documentó envíos de recuas de acémilas en las actas capitulares de Murcia por esta época ${ }^{39}$. Muy conocida y de gran repercusión fue la toma de Overa al asalto por el lorquino Tomás de Morata, constituyendo un honor para el linaje que sería recordado tras la conquista definitiva con la concesión de la alcaidía a su hijo homónimo y los hechos ensalzados posteriormente por cronistas y eruditos como Pérez de Hita, Morote o Cánovas Cobeño en los cronicones de la ciudad de Lorca ${ }^{40}$. A ello se unieron otras cabalgadas, quemas, talas y expediciones de saqueo por la cuenca del Almanzora y el valle de Purchena, llegando incluso a lugares tan alejados como Níjar, con el objetivo de imponer una sensación de peligro que permitiese un cierto grado de control de la zona; expediciones que tuvieron sus correspondientes contrapartidas por parte granadina.

Mientras tanto, don Fernando Álvarez de Toledo no había parado tampoco de establecer negociaciones con las autoridades musulmanas de plazas como Cambil o Castril, intentando su sometimiento a Castilla, con tratos sobre cautivos de Baza y Guadix con los musulmanes o completando la ocupación de Arenas; si bien por la zona occidental de la frontera se sucedían varios desastres en Écija, Archidona y, el más grave, la muerte del conde de Niebla, don Enrique de Guzmán, ahogado al volcar su barca en el infructuoso intento de recuperar Gibraltar ${ }^{41}$.

Pero si a todo ello sumamos las talas y daños efectuados por los cristianos en las vegas de Guadix, Baza y Granada, junto con la importante conquista de Huelma, bastión esencial de la frontera de Jaén (junto con otras plazas de menor entidad), por un contingente dirigido por el sucesor de don Fernando al frente de

38. J. de M. Carriazo (ed.). Crónica del Halconero de Juan II..., op. cit., pp. 226-227. Amplía la información el profesor J. E. López de Coca, Op. cit., p. 653.

39. Sobre la conquista de Albox, su dominio cristiano y su posterior pérdida, sigue siendo referencia el artículo de J. Torres Fontes. "Conquista castellana y pérdida de Albox en el reinado de Juan II (1436-1445)", en Instituciones y sociedad..., op. cit., pp. 463-474. Pub. originalmente en Roel. Cuadernos de Civilización de la Cuenca del Almanzora, 1, 1980, pp. 35-41.

40. Cfr. J.F. Jiménez Alcázar. Huércal y Overa. De enclaves nazaries a villas cristianas (12441571), Huércal-Overa, Ayuntamiento de Huércal-Overa, 1996 pp. 17, 19, 46-47.

41. J. Torres Fontes. Xiquena..., op. cit., pp. 59-60. 
la capitanía de la frontera de Córdoba y Jaén, don Íñigo de Mendoza, señor de Hita y Buitrago, en $1438^{42}$, se nos traza una perspectiva bastante favorable a Castilla en la guerra contra Granada en un momento en el que la guerra civil y el secular enfrentamiento nobleza-monarquía impidieron un mayor avance y determinaron el fin de las conquistas ${ }^{43}$.

\section{FRONTERA DE GRANADA (SECTOR ORIENTAL, 1433-1439)}

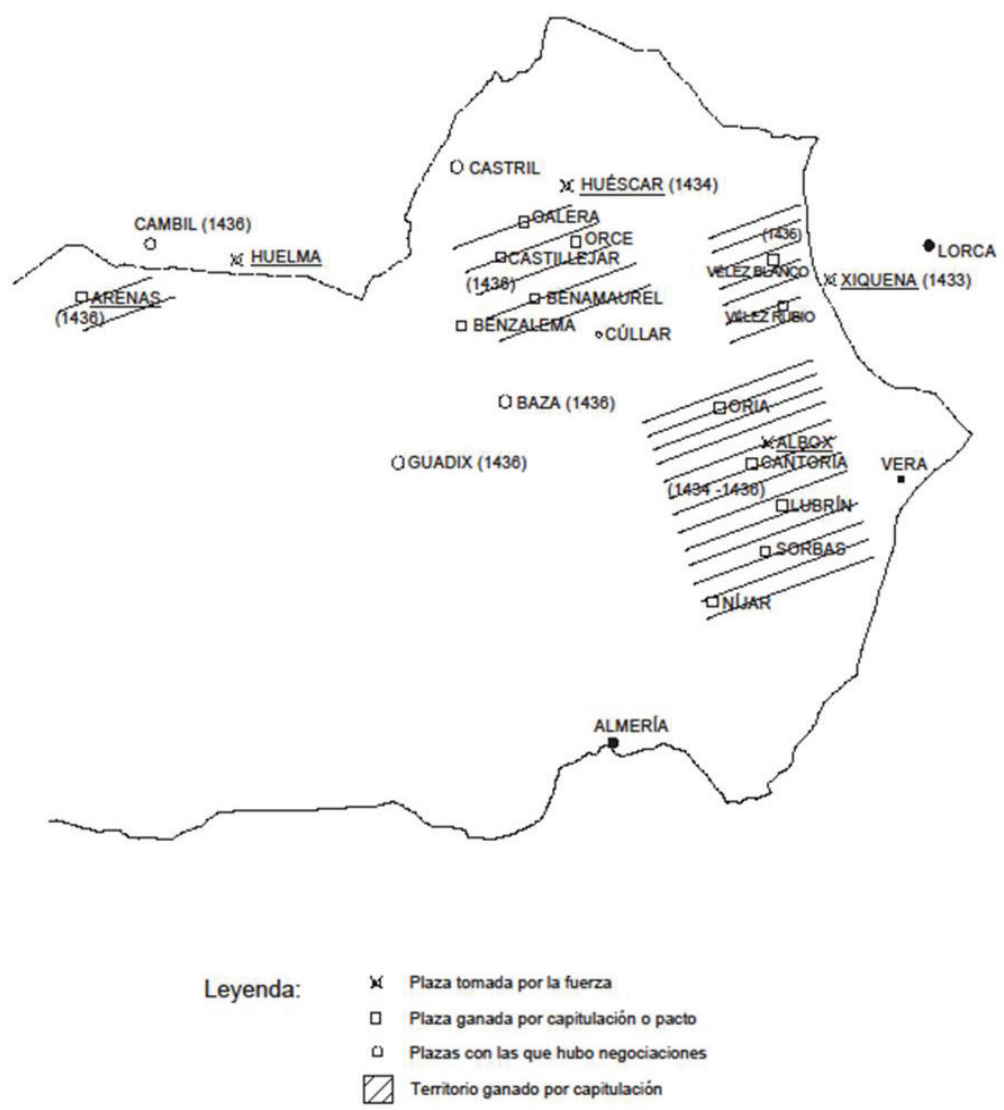

Mapa 2. La frontera de Granada (sector oriental, 1433-1439). Fuente: Elaboración Propia.

42. F. Pérez de Guzmán, L. Galíndez de Carvajal. Crónica del señor Rey don Juan..., p. 384.

43. Los enfrentamientos nobleza-monarquía fueron magistralmente estudiados por L. Suárez Fernández. Nobleza y monarquía: entendimiento y rivalidad. El proceso de la construcción de la Corona española, Madrid, 2003. 
Fue precisamente a don Íñigo, en el cargo de capitán mayor de la frontera de los obispados de Córdoba y Jaén, a quien se le encomendó la formalización de una tregua con Granada en 1439. En ella se incluían las plazas ganadas hasta ese año, citándose para la frontera oriental las siguientes: Arenas, Huelma, Bexis, Benzalema, Benamaurel, Castilléjar, Galera, Huéscar, Torralba, Segura, Orce, Vélez Rubio, Vélez Blanco, Tirieza, Albox, Bédar y Cuevas de Belda (probablemente Cuevas de Almanzora). A ellas Garci Sánchez, jurado de Sevilla, añadiría en sus Anales del siglo XV Cúllar; mientras que Diego Rodríguez de Almela incluyó Alicún de Ortega, Cabrera, Arboleas y Cantoria y, ya en el siglo XVII, el licenciado Francisco de Cascales a Partaloa y Albánchez. Por su parte, Merino Álvarez también cita Zurgena y Overa ${ }^{44}$. La tregua fue concertada por tres años y sería prorrogada por otros tres en $1443^{45}$.

Gracias en parte a esa tregua, hasta 1444, con Castilla enfrascada en discordias internas, no tendremos noticias de movimientos importantes en la frontera con Granada, obteniendo un mapa prácticamente inalterable y reflejo del gran avance anterior $^{46}$.

No hemos de olvidar sin embargo, que el avance castellano había sido posible gracias a la situación interna granadina, con la jassa o élite dirigente dividida entre varios reyes o pretendientes a ocupar el trono granadino, discordias que habían sido aprovechadas por la corte castellana para intervenir y menoscabar el poder nazarí. Así sucedió cuando Juan II acogió en la Corte a Yusuf IV Ibn al-Mawl (el Abenalmao de las crónicas), el cual le prometía vasallaje en las inmediaciones del campo de la Higueruela y a sus partidarios (entre ellos los Venaceite de Guadix), con un Muhammad IX "el Zurdo" incapaz de controlar los resortes del poder pero que al final acabó por asentarse en el trono granadino por tercera vez (1432-1445) frente a Ibn al-Mawl, caído en desgracia. Periodo que coincide, al menos hasta 1439 , con los sucesos de la guerra castellano-granadina que hemos analizado, cuando Juan II apoya al caudillo Abenamar del romance (probablemente Yahya de nombre, nos aventuramos a pensar que referido al que acabara siendo infante de Almería y padre del $\mathrm{Nayar}^{47}$ ) frente a "el Zurdo"; acepta el sometimiento de villas y localidades enemigas de éste y refugia en su corte a muchos de sus detractores.

44. Seguimos para estos datos a J. Torres Fontes. Xiquena ..., pp. 66-68.

45. J.E. López de Coca Castañer. "Castilla, Granada y la tregua de 1443”, en V.Á. Álvarez Palenzuela, M.Á. Ladero Quesada, J. Valdeón Baruque (Coords). Estudios de Historia Medieval. Homenaje a Luis Suárez, Valladolid, 1991, pp. 301-313, pp. 309-311.

46. Véase mapa 2.

47. Vid. R. Salicrú i Lluch. Op. cit., pp. 359-361. Sobre Cidi Yahya al-Nayar, que rindió Baza a Fernando "el Católico", denominado por las fuentes como infante de Almería por herencia de su padre Aben Celin y su ascendencia, siguen siendo de referencia aún a día de hoy los datos que aportaron en su día M. Espinar Moreno y J. Grima Cervantes. "Un personaje almeriense en las crónicas musulmanas y cristianas. El infante Cidi Yahya Alnayar (1435?-1506): su papel en la Guerra de Granada”, Boletín del Instituto de Estudios Almerienses, 7 (1987), pp. 57-83; y “Testamento y muerte de don Pedro de Granada”, Mayurqa, 22 (1989), pp. 239-254. También son interesantes los aspectos contenidos en el artículo de $\mathrm{M}^{\mathrm{a}}$ del C. Calero Palacios y R.G. Peinado Santaella. "Fuentes para el estudio de la nobleza y los señoríos del reino de Granada: el inventario del archivo del Marquesado de Campotéjar (1682)", Revista del Centro de Estudios Históricos de Granada y su Reino, Segunda época, 1, 1987, pp. 239-260. 
Esa participación en ese inmenso tablero de ajedrez en este caso favoreció a Castilla, si bien, como veremos más adelante, en otros momentos le perjudicó, como en los convulsos años de 1445 a 1450 cuando los rebeldes a Muhammad IX fueron Yusuf V e Ismail.

\section{LA CONFIGURACIÓN INSTITUCIONAL DEL TERRITORIO CONQUISTADO}

La rapidez y continuidad de las conquistas expuestas más arriba dio lugar a que pronto se iniciara la organización y configuración institucional del territorio anexionado, proceso que se llevaría a cabo partiendo de las experiencias previas, valiéndose de las estructuras administrativas que habían funcionado en los procesos de conquista y repoblación del siglo XIII y de las instituciones de las zonas cercanas. Dos instituciones de gobierno y organización aportadas por Castilla condicionarían la integración y absorción del territorio al conjunto. Hablamos fundamentalmente del concejo, principal vía de organización municipal; y del obispado, forma básica de organización de cualquier territorio cristiano.

No cabe duda de que para consolidar el dominio sobre un territorio, no hay nada mejor que poblarlo. Pero, como veremos, diversas circunstancias imposibilitaron establecer mecanismos repobladores en todas las plazas conquistadas.

Uno de los lugares en los que la Corona impulsó el proceso repoblador con más ahínco fue Huéscar, comprendiendo su importancia estratégica como bastión defensivo del sector noreste de la frontera granadina y base de expediciones de castigo. Así, una vez conquistada, Juan II se apresuró a enviar órdenes a los capitanes de la frontera de la zona de Córdoba y Jaén y de Murcia para que colaboraran en la defensa de la plaza. Pronto vendrían varios privilegios de exención de moneda e impuestos para favorecer la repoblación de la villa, privilegios que, por sus ventajosas condiciones, ocasionaron una importante pérdida demográfica en la ciudad de Murcia, según documentó Juan Torres Fontes ${ }^{48}$, ya que la exención en el pago de impuestos era lo más cercano al concepto medieval de libertad, puesto que abría las vías para el ascenso social. Por otro lado, el mantenimiento de la plaza en poder de la Orden de Santiago suponía asegurarse el control militar de la zona y, a su vez, el alejamiento de la frontera hacia el Oeste favorecía el aumento demográfico en los dominios santiaguistas del Reino de Murcia, incluida la propia Huéscar, donde se desplazaban contingentes de las villas limítrofes (Moratalla, Letur...) en busca de nuevas tierras para roturar ante el control del espacio ganadero por parte de las oligarquías en las zonas de procedencia, según constató Rodríguez Llopis ${ }^{49}$.

Con la conquista e incipiente repoblación se implantó el sistema de organización municipal típicamente castellano: el concejo. Un concejo al modo de los

48. Vid. J. Torres Fontes. "Conquista y pérdida de Huéscar...”, art. cit., pp. 450-451.

49. M. Rodríguez Llopis. Señoríos y feudalismo en el Reino de Murcia: los dominios de la Orden de Santiago entre 1440 y 1515, Murcia, 1986, pp. 72-75. 
de realengo pero en manos de la Orden de Santiago, al frente del cual se situó como alcaide el propio Rodrigo Manrique ${ }^{50}$. La composición del mismo, en fecha creemos que posterior, cercana quizá a la pérdida o anterior (ca. 1445/47), la conocemos a través de la súplica que dirigen sus miembros al deán y cabildo de la Iglesia de Cartagena pidiéndole que permitiese que se quedaran como limosna las rentas y diezmos de ese año para garantizar el sostenimiento de los turnos de rondas y velas, ante la falta de proveimiento de la plaza por parte del rey a causa de los muchos trabajos suyos. Rubricándola aparecen cuatro regidores, Álvaro de Madrid, Ruy Fernández, Álvaro de Santacruz y Gonzalo Fernández, junto con el jurado Juan Mateos, y la intitulación es la prototípica de esta tipología documental para un concejo castellano: el conçejo, alcayde, alcaldes, alguasil, regidores, caualleros, escuderos, ofiçiales e omes buenos de la villa de Huéscar ${ }^{51}$.

A día de hoy, según los datos con los que contamos, podemos decir que la repoblación sólo tuvo éxito, y por poco tiempo, en esta villa, quedando materializada en el asentamiento institucional de un concejo cristiano y en el mantenimiento de una población al menos durante los primeros años. Poco tiempo hubo de durar este espejismo sin embargo, ya que pronto el desabastecimiento se apoderaría de la villa y, como el resto de dominios de Rodrigo Manrique, se vería envuelta en la prolongación de la guerra civil castellana a Murcia (al ser el comendador un actor destacado en la contienda) y en las disputas entre los Fajardo.

En las restantes plazas ganadas, fue mucho más difícil impulsar el proceso repoblador debido a varios factores. En primer lugar, la lejanía de algunas de ellas con respecto a sus posiciones de vanguardia las convertía en lugares inseguros y desprotegidos, difíciles no ya de poblar, sino de mantener en ellas guarniciones para evitar que cayeran frente al enemigo, como en el caso de Albox, que acabaría sucumbiendo a finales de agosto de $1445^{52}$. En segundo lugar, muchas de las fortalezas ahora bajo dominio castellano se habían entregado por oposición a Muhammad IX mediante unas capitulaciones que les habían sido confirmadas por Juan II, según las cuales se les respetaban sus propiedades, religión, instituciones, fiscalidad... con lo cual la población cristiana se limitaba a pequeñas guarniciones y el único cambio constatable había sido el traspaso de la soberanía. Es el caso de la mayoría de ellas, como Vélez Blanco, Vélez Rubio, Galera, Castilléjar, Orce y Benamaurel. Bastó el cambio de la situación, con el advenimiento de Yusuf V e Ismail como pretendientes al trono granadino y el debilitamiento de las posiciones castellanas, para que pronto se perdieran, siendo recuperadas al postularse a favor de alguno de los candidatos. Por otro lado, el propio carácter fronterizo de muchas plazas complicaba el asentamiento de población, como sucedería en el caso de Xiquena (Tirieza había sido destruida tras su incorporación en 1433 para evitar sorpresas de nuevo, como había sido la traición de su alcaide Pascual de Zalame-

50. Prestaba pleito homenaje como tal a su tío, Fernando Álvarez de Toledo, el día 16 de noviembre de 1434, a las puertas del castillo oscense. Cfr. J.E. López de Coca Castañer. "Fernando Álvarez de Toledo...", op. cit., pp. 649-650.

51. Cfr. Apéndice documental, doc. $\mathrm{n}^{\circ} 3$.

52. Vid. J. Torres Fontes. "Conquista castellana y pérdida de Albox...”, pp. 471-474. 
da, que, convertido al Islam, había entregado la villa al enemigo). A ello hay que unirle la propia inestabilidad política en la que se sumió el Reino de Murcia con la guerra civil entre los Fajardo sobre todo a partir de 1445 y el proceso de "señorialización" de la zona en manos de los linajes Fajardo y Manrique, de un lado, y Pacheco de otro. En este sentido, hay que recordar aquí los intereses aludidos del marqués de Villena en Xiquena, de donde llegó a obtener el título de conde, embolsándose el dinero para la repoblación y conseguiendo de Enrique IV en 1470 un privilegio de homicianos de escasa efectividad ${ }^{53}$.

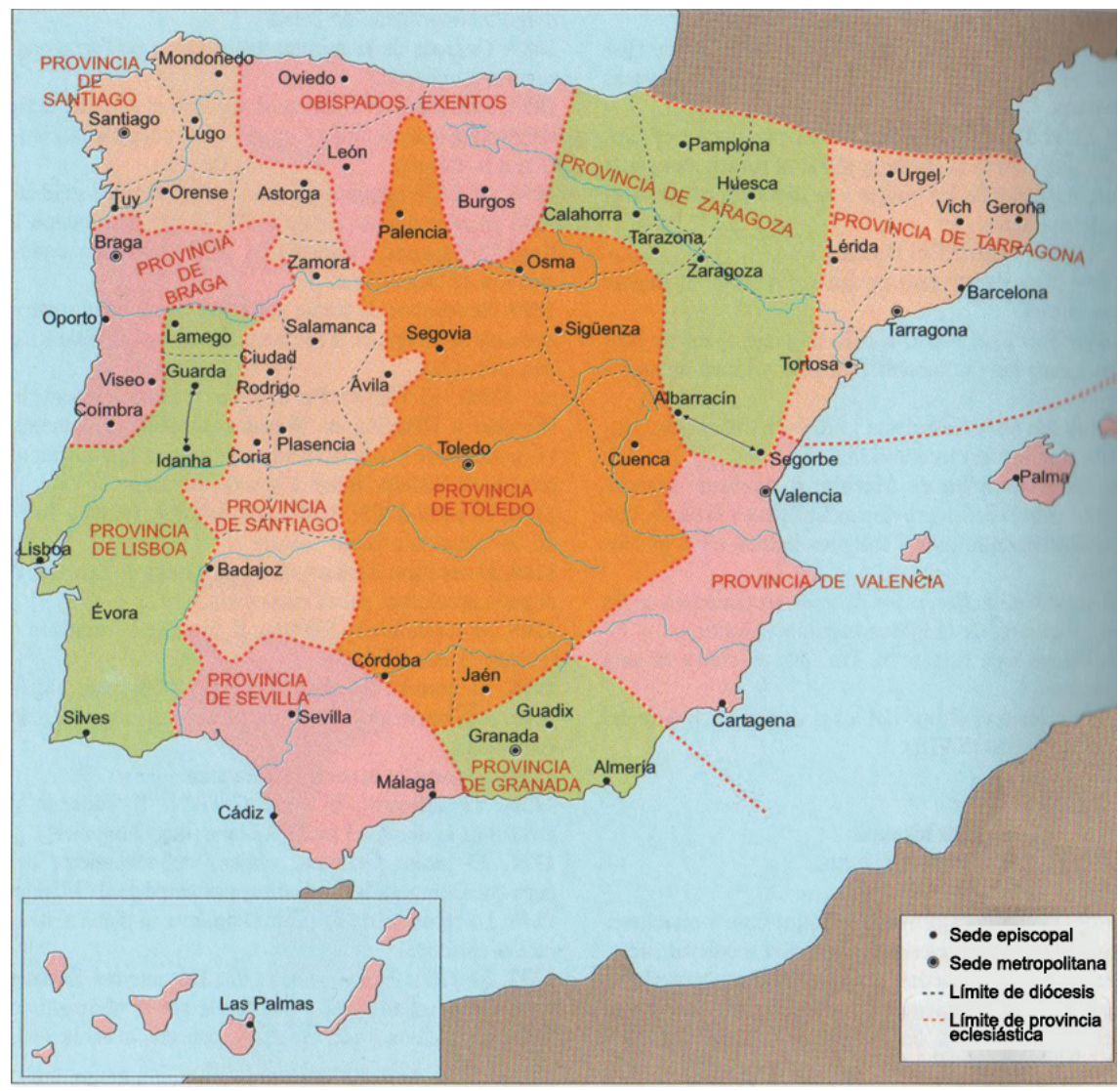

Mapa 3. Diócesis peninsulares en la Baja Edad Media. Fuente http://reinolvidado.blogspot. com.es/2006_06_01_archive.html.

53. Sobre las circunstancias que movieron la concesión de este privilegio para la villa del marqués de Villena y conde de Xiquena, véase el artículo de J.F. Jiménez Alcázar, J. Ortuño Molina. “El privilegio de repoblación de Xiquena (s. XV)...”, op. cit. 
Otra cuestión básica a la hora de organizar el territorio conquistado es la organización eclesiástica. No olvidemos que las conquistas suponían en la lógica de la ideología reconquistadora la reincorporación de tierras a la Cristiandad, y la célula esencial de organización de un territorio cristiano es el obispado.

Ya desde la primera delimitación formal de la diócesis de Cartagena, realizada por Alfonso X en 1266 tras la restauración de la sede en 1250 por bula de Inocencio IV, quedaron claras las pretensiones del Obispado sobre las zonas más orientales del Reino de Granada. Así, en 1271 el maestre de Santiago, Pelay Pérez Correa, aceptaba mediante concordia con el obispo que se integrasen bajo la autoridad del prelado de Cartagena las tierras de Moratalla, Huéscar, Puebla de don Fadrique (Volteruela), Galera, Orce y Castril, si bien en 1314 los granadinos recuperaban todas las plazas a excepción de Moratalla ${ }^{54}$. Por el Sur, se consiguió de Sancho IV un privilegio, dado en Valladolid, el 4 de octubre de 1293, mediante el cual se donaban a la diócesis de Cartagena los territorios de Oria et Cantoria et Muxácar et el valle de Porchena et los Vélezes, que son agora de moros, que los ayan quando Dios quisiere que sean de christianos [...] e commo lo solían aver en otro tienpo segúnd se cuenta en la Coronica vieja ${ }^{55}$. Se trataba de una donación ciertamente vaga y atemporal que la paralización de las conquistas castellanas por la zona impidió que se llevase a buen puerto en el corto plazo, pese a lo cual la Iglesia de Cartagena tendría especial cuidado en que este privilegio le fuese confirmado una y otra vez por los sucesivos monarcas hasta los Reyes Católicos ${ }^{56}$ Mientras tanto, no cesaron las pretensiones del obispado cartaginense hacia el Oriente del Reino de Granada, por la zona del valle del Almanzora. Así, en 1309 se conquistaba el castillo de Lubrín por las armas del obispo de Cartagena, que lo denominó de San Pedro, pero su lejanía, aislamiento y amenaza de la cercana Vera nazarí, llevó al prelado a cambiarlo por los señoríos de doña María de Molina en el Reino de Murcia: Alguazas, Alcantarilla, el real de Monteagudo y algunas propiedades en la capital ${ }^{57}$.

Es precisamente en el periodo cronológico que estudiamos cuando estuvieron más cerca de materializarse las viejas aspiraciones de la diócesis de Cartagena en el Reino de Granada tras la donación de Sancho IV, dado el gran avance conquistador de la década de los treinta del siglo XV. El proceso no estuvo exento de conflictos con el arzobispado de Toledo en la zona de Huéscar, como había

54. J. Torres Fontes. Documentos del siglo XIII, CODOM, II, Murcia, 1969, pp. 39-41.

55. J. Torres Fontes. Documentos de Sancho IV, CODOM, IV, Murcia, 1977, doc. CLIV, pp. $142-144$

56. Así, Pedro I (1353, septiembre, 4. Valladolid); Enrique II (1371, septiembre, 12. Toro); Juan I (1379, agosto, 9. Burgos); Juan II (1420, febrero, 25. Valladolid) y los Reyes Católicos (1476, septiembre, 28. Tordesillas), tal y como se contiene en la relación de privilegios y bulas de la Iglesia de Cartagena del ACM. Algunos de estos documentos han sido publicados: Vid. Á.L. Molina Molina. Documentos de Pedro I, CODOM, VII, Murcia, 1978, doc. 57; L. Pascual Martínez. Documentos de Enrique II, CODOM, VIII, Murcia, 1983, doc. LXXXII, pp. 113-115.

57. La referencia la tomo de J. Torres Fontes. "El señorío del Valle del Almanzora en la Edad Media”, en Instituciones y sociedad..., op. cit., pp. 365-383, p. 377. Pub. originalmente en Roel, 2 (1981), pp. 17-26. En este artículo puede verse una evolución de las aspiraciones, concretadas o no, del obispado de Cartagena sobre el valle del Almanzora entre el siglo XIII y el XVI. 
sucedido tiempo atrás con la encomienda santiaguista de Segura de la Sierra ${ }^{58}$. Así, recién tomada la villa en 1434, Martín Carrión, en representación del obispo, deán y cabildo de la Iglesia de Cartagena, acudió a tomar posesión y a consagrar la casa de oración de Huéscar, así como sus anejos de Orce, Galera y Castilléjar para cada e quando a Dios pluguiese que fuesen de christianos, que confiaua en Dios que sería çedo, presentando carta de poder del obispo Diego de Bedán por la cual le facultaba a él, a Diego Martínez de Rubielos, arcipreste de la villa de Lorca, y a Juan Sánchez de Clares, vicario de Segura, para tomar posesión de todo ello. Fue entonces cuando Alfonso Gómez, vecino de Alcaraz y procurador de la Iglesia toledana, alegó derechos en nombre de la silla primada, que no le fueron reconocidos por no contar con el apoyo del comendador Rodrigo Manrique y por falta de argumentos válidos y pruebas documentales ${ }^{59}$.

La toma de posesión de los lugares de oración de Huéscar fue el inicio de un intento de organización administrativa de la zona que se pretendió llevar a cabo ante un proceso de conquista que parecía irreversible. Así, pronto (hacia 1436 según Rodríguez Llopis e Isabel García Díaz) ${ }^{60}$, se proyectó la creación de dos arciprestazgos en las nuevas zonas conquistadas, uno en Huéscar y el otro en Vera. El primero integraría la zona norte del sector oriental del reino granadino, desde Xiquena y Tirieza hasta Huéscar y Castilléjar; mientras que el segundo abarcaría la zona sur, desde Mojácar a Vera y los lugares del valle del Almanzora y Purchena concedidos por privilegio de Sancho $\mathrm{IV}^{61}$. Sin embargo, la realidad de los hechos determinaría que todo quedara en poco más que un proyecto.

Más tarde, en el Fundamento de Diego de Comontes, obra escrita por este obispo de Cartagena hacia 1447, aparece un préstamo en Arboleas, dos beneficios sin cura en la iglesia de Santa María de Huéscar y uno curado en la de Santiago de la misma villa, otro en Galera y otro en Castilléjar, citándose también la presencia de un religioso en Albox, dependiente del arciprestazgo de Lorca ${ }^{62}$. Así pues, la organización eclesiástica de este momento se realizó desde el obispado de Cartagena, no tanto por cercanía, sino por la alegación de derechos históricos por parte de dicha institución.

Lo cierto es que, al menos desde el punto de vista económico, sí estuvo funcionando la recaudación de los diezmos de Huéscar, documentada al menos entre los años 1438 y $1441^{63}$.

58. Véase mapa 3.

59. Cfr. Apéndice documental $\mathrm{n}^{\mathrm{o}} 1$.

60. Cfr. M. Rodríguez Llopis, I. García Díaz. Iglesia y sociedad feudal. El cabildo de la Catedral de Murcia en la Baja Edad Media, Murcia, Universidad de Murcia, 1994, pp. 23-24.

61. Cfr. Apéndice documental $\mathrm{n}^{\circ} 2$.

62. J. Torres Fontes, Á.L. Molina Molina (ed.). Fundamento de la Santa Iglesia y de toda la Diócesis de Carthagena, escrito y ordenado por el Ilustrísimo señor don Diego de Comontes, Murcia, estudio y edición facsímil de la de 1756, Real Academia Alfonso X El Sabio, 2009, f. 25r/v, 41v-42r

63. El documento se conserva en ACM, leg. 208, exp. 1151. Un resumen a modo de síntesis en dos cuadros puede verse en la obra de M. Rodríguez Llopis, I. García Díaz. Iglesia y sociedad feudal..., op. cit., p. 136. 
Pero todo se vino al traste en poco tiempo. La reacción granadina del bienio 1445-1447 trajo como consecuencia un retroceso a la línea fronteriza de 1430, con la pérdida de todas las plazas ganadas hasta entonces, con la sola excepción de Xiquena y Tirieza. Con ello caían en saco roto los deseos, proyectos y primeras realidades de configuración institucional de un territorio que, por parte eclesiástica, ya no dependería del obispado de Cartagena, pues con la creación de los obispados de Guadix y Almería los Reyes Católicos solventaron las disputas con Toledo. Sólo Huércal y Overa, incorporadas al término de Lorca, acabarían bajo los dominios del prelado de Cartagena, no sin pleito por la recaudación de los diezmos en el XVI con el nuevo obispado almeriense ${ }^{64}$.

\section{LA CONTRAOFENSIVA GRANADINA DE 1445-1447}

La tregua de 1439 había supuesto el reconocimiento y consolidación de los territorios conquistados hasta ese momento, es decir, se reconocía a Castilla el dominio de un amplio territorio fruto de un avance fronterizo importante. Sin embargo, como señaló en su día Veas Arteseros, el hecho de no haber sido ocupadas Baza y Vera planteaba un interrogante sobre la consolidación de ese dominio, ya que la lejanía de las posiciones con respecto a sus centros de aprovisionamiento económico y militar (Lorca, Caravaca, Segura), las convertía en reductos inconexos unos de otros a merced del enemigo ${ }^{65}$.

$\mathrm{Su}$ mantenimiento en manos castellanas fue posible fundamentalmente gracias a la situación interna del Reino de Granada, envuelto en luchas civiles entre partidarios de Muhammad IX y Yusuf IV y en un clima de desprotección frente al enemigo, enemistades y apoyos a uno u otro bando que había llevado a muchas poblaciones a solicitar capitulaciones para evitar males mayores. Fue en ese ambiente de inestabilidad nazarí en el que se renovó la tregua de 1439 en 1443 por tres años que expiraban en abril de $1446^{66}$.

Pero pronto cambiaron las cosas, porque la situación interna de Castilla no era mucho mejor que la del reino nazarí, ya que la guerra civil y las pugnas nobiliarias socavaban los cimientos de una débil Monarquía encarnada en la persona de Juan II y la frontera quedaba desprotegida a su suerte, abandonada a la acción de aventureros sin principios que no dudaban en pactar con el enemigo cercano para el cumplimiento de objetivos inmediatos. Esa guerra tuvo precisamente entre 1444 y 1445 como uno de sus escenarios principales al Reino de Murcia. En estas tierras encontramos por entonces a muchos de los protagonistas de la lucha, como el príncipe don Enrique, el condestable don Álvaro de Luna, el infante don

64. En el ACM, leg. 208, exp. 1153, exp. 1155 y exp. 1156 se encuentra el traslado autorizado del pleito abierto en la Chancillería e Granada en 1530 entre el obispado de Cartagena y el de Almería por los diezmos de Huércal y Overa, que no llegó a cerrarse a favor de la Iglesia de Cartagena hasta 1552.

65. F. de A. Veas Arteseros. "El obispado de Cartagena. Una frontera político-religiosa", Murgetana, 114 (2006), pp. 19-51, pp. 38-39.

66. J.E. López de Coca Castañer. "Castilla, Granada...”, op. cit., p. 311. 
Enrique, maestre de Santiago luego desposeído de su maestrazgo, o el comendador Rodrigo Manrique, ahora rebelde a Juan II y a su valido don Álvaro de Luna. Pero además hay que contar con dos hechos determinantes: la muerte del infante don Enrique en la batalla de Olmedo en 1445 y la del adelantado Alonso Yáñez Fajardo en marzo de 1444, que había puesto fin a la vida de un hombre autoritario y exigente que había sido capaz de mantener bajo su control el territorio; quedando entonces en el cargo un niño, don Pedro, y una viuda, doña María de Quesada, que enseguida tuvieron que hacer frente a las pretensiones de otro miembro del linaje, el alcaide de Lorca, Alonso Fajardo, quien no dudaría en ayudarse de tropas granadinas para sus propósitos. A partir de entonces todo iba a ser una lucha de bandos y de todos contra todos, dejando a un lado el abastecimiento y el apoyo a las guarniciones fronterizas.

Un buen indicativo de ese abandono pueden ser las amargas súplicas antes referidas del concejo de Huéscar al deán y cabildo del obispado de Cartagena en una fecha indeterminada pero que creemos cercana a $1445^{67}$. En la carta los munícipes pedían apoyo económico mediante una parte de las rentas y diezmos con objeto de poder mantener los turnos de ronda y velas, ya que el rey no proveía la villa (esto creemos que lo causa los muchos trabajos suyos, señalaban) con la consiguiente despoblación y peligro de que la plaza sucumbiera frente al enemigo ${ }^{68}$.

No sabemos cuál fue la respuesta del cabildo diocesano, pero en cualquier caso lo que estaba claro es que el desenlace estaba cantado, antes o después, para la villa de Huéscar y para otras muchas de su entorno. En la misma carta, los miembros del concejo calificaban la situación de la villa como la de aquel que dice sácame deste barranco, degüéllame en el otro ${ }^{69}$.

Lo cierto es que, pese a la falta de abastecimiento de las plazas, desde la Corona no se dejó de aplicar una política de intromisión en las discordias granadinas entre Muhammad IX “el Zurdo”, su sobrino Yusuf V “el Cojo” y el infante Ismail mediante el apoyo a éste último, con el fin de menoscabar el poder nazarí ${ }^{70}$. Pero la discordia también afectaba a Castilla, y así, en el Reino de Murcia, la facción que apoyaba a don Juan de Navarra, encabezada por Alonso Fajardo, colaboraba con Yusuf V (que contaba también, dicho sea de paso, con la ayuda de Alfonso V "el Magnánimo"), en detrimento de Juan II. Dominando Yusuf la parte oriental del solar granadino, y aprovechándose de la mencionada inestabilidad, impulsaría varias

67. Para la datación en ese año nos basamos en que la situación desesperada transmitida por la carta parece acercarnos a una fecha próxima a que la villa de Huéscar cayese de nuevo en manos musulmanas. Por otra parte, el hecho de que no se nombre en la dirección de la carta al obispo y sólo al deán y cabildo de la diócesis de Cartagena pudiera ser indicativo de que la sede estaba vacante, y al parecer lo estuvo entre 1442 y 1447, entre los episcopados de fray Diego de Bedán y don Diego de Comontes.

68. Cfr. Apéndice documental $\mathrm{n}^{\circ} 3$.

69. Apéndice documental $\mathrm{n}^{\circ} 3$.

70. Gracias a la revisión de la serie cronológica de los soberanos granadinos efectuada en su día por Roser Salicrú quedan resueltas las dudas existentes acerca de la figura de "el Cojo", identificado claramente con Yusuf V, y descartándose la existencia de Muhammad X. Cfr. R. Salicrú i Lluch, $O p$. cit., pp. 381-390 y cuadros genealógicos finales. 
acciones para recuperar las plazas perdidas a costa de los castellanos, contando el caudillo Ibrahim ibn Abd al-Barr a decir de Ibn Asim con la connivencia de Rodrigo Manrique en la entrega de Galera y Castilléjar, dadas sus buenas relaciones con Yusuf V, pues ambos tenían las pretensiones de apoderarse del Reino de Murcia ${ }^{71}$. Además de estas dos plazas, fueron volviendo a dominio nazarí paulatinamente entre 1445 y 1447 Huéscar, Benamaurel, Benzalema, Orce, los dos Vélez (con intervención de Ibn Abd al-Barr, del alcaide de Guadix y de Yusuf ibn Kumasa de Baza) y los lugares del valle del Almanzora (Hisn al-Banyis y Hisn al-Bariy, por parte de Al-Abbas ibn Ali ibn Hamid, alcaide de Vera), Arenas y Hisn al-Sikka (cerca de Alcalá la Real) en la parte central, con lo cual la línea fronteriza volvía de nuevo a la de la década de 1430, quedando en manos castellanas en la zona oriental únicamente Xiquena y Tirieza. Particularmente interesante fue la reconquista granadina de Huéscar que, según la Yunna de Ibn Asim, ministro de Muhammad IX y testigo ocular, se debió a las discordias entre Yusuf V y su ministro Ibn Allaq, el cual, llevado del rencor, buscó ayuda en los cristianos para tomarle posesiones al sultán: entre esos cristianos figuraban como personajes principales casualmente Rodrigo Manrique y Alonso Fajardo "el Bravo". Enterados en la corte de Yusuf de la rebeldía, éste se aprestó a sofocarla mediante un ejército capitaneado por Abu1-Abbas ibn Hamid, alcaide de Baza, el cual condujo al rebelde hasta Huéscar y lo derrotó, ganando la plaza para Yusuf. Por su parte, Muhammad IX, bajo cuyo dominio se situaba esencialmente en la parte occidental del emirato, recuperó muchas de las plazas perdidas por aquella zona, como Hisn Nuh (Macharno, puerto fronterizo entre Málaga, Comares y Vélez Málaga), Ayamonte o Pruna, entre otras, según las fuentes árabes, que también mencionan la conquista de Antequera ${ }^{72}$.

La Crónica del Halconero es bien explícita en las razones aducidas por los cristianos para las pérdidas, que hemos apuntado más arriba:

E perdiéronse por no estar vasteçidas, e syn cargo de los alcaides, por quanto ellos rrequirieron por muchas vezes al Rey que las mandase prouer e vastecer, pero el Rey non lo pudo fazer ni conplir, según las grandes neçesidades en que a la sazón estaua, por causa de los dichos voliçios e discordias ${ }^{73}$.

Habría que esperar a la guerra final, ya en el reinado de los Reyes Católicos, para que los territorios perdidos se reintegraran a la Corona castellana, esta vez de manera definitiva. Pero para entonces muchas cosas habrían cambiado y la

71. R. Salicrú i Lluch. Op. cit., pp. 397-398.

72. Sobre los detalles de la pérdida de las plazas referidas, pueden verse las distintas contribuciones del profesor Torres Fontes citadas a lo largo de este trabajo. Un análisis pionero del proceso reconquistador por parte nazarí desde las fuentes árabes, esencialmente a través de la Yunna de Ibn Asim, en la aportación de Abdelghaffar Ben Driss a los Estudios de Frontera de Alcalá la Real. Cfr. A. Ben Driss. "La frontera granadino-castellana en la primera mitad del siglo XV", en I Estudios de Frontera. Alcalá la Real y el Arcipreste de Hita, Jaén, 1997, pp. 41-48. Más actualizado, y con una perfecta colación de todas las fuentes cristianas y árabes, en la obra citada de Roser Salicrú: vid. R. Salicrú i Lluch. Op. cit., pp. 390-426.

73. J. de M. Carriazo (ed.). Op. cit., p. 488. 
política de "señorialización" del Oriente del Reino de Granada, junto con la erección de los obispados de Almería y Guadix terminaría por configurar un nuevo organigrama.

\section{CONCLUSIONES}

El gran avance castellano sobre la frontera granadina durante la década de los treinta del siglo XV no fue el resultado de una política decidida, planificada y cohesionada desde un poder central por entonces debilitado, sino más bien la consecuencia de acciones individuales y combinadas de nobles y caudillos fronterizos de los distintos sectores de la misma, aprovechando la situación de discordia interna en el reino nazarí, por lo que su mantenimiento en buena medida iba a depender del juego de intereses de dichos personajes.

A través de algunos documentos del Archivo de la Catedral de Murcia, hemos podido comprobar cómo se llevaron a cabo intentos de configuración y organización administrativa desde el mismo momento de las conquistas que tuvieron algunos resultados de escaso recorrido temporal. Estos intentos se llevaron a cabo desde las zonas más cercanas, como los reinos de Jaén y Murcia y obispados de Córdoba, Jaén y Cartagena, alegando derechos de épocas pasadas y utilizando estructuras institucionales próximas y previas para la incorporación de los nuevos territorios (como el arciprestazgo de Lorca).

El proceso no estuvo exento de complicaciones, como la tensión con el arzobispado de Toledo, que alegaba derechos sobre Huéscar, la falta de abastecimiento de las plazas por la situación interna de Castilla, o las pretensiones e intereses de algunas de las personalidades que intervinieron en los hechos, como el propio don Rodrigo Manrique, vacilante entre la lealtad y la traición a la Corona, llegando a pactar incluso con Yusuf V para conseguir sus propósitos. Así pues, pese a que la repoblación fue exitosa en algunas zonas al principio (particularmente en Huéscar), y se pudieron crear las estructuras institucionales para mantenerla y asentarla funcional e ideológicamente (concejo y arciprestazgos, sistemas de recaudación impositiva), pronto se iba a demostrar la precariedad de las conquistas. Precariedad que venía determinada, en primer lugar, por la propia dinámica en que se habían producido (muchas de ellas mediante capitulaciones o acciones realizadas en el marco de grandes tableros de ajedrez); en segundo lugar, por su aislamiento (ya que muchas veces se encontraban cercanas a plazas fuertes nazaríes y alejadas de sus centros provisores) y, en tercer lugar, por su desabastecimiento (entre otras razones debido a las convulsiones que afectaron a Castilla y a Granada por aquellos años). De esta manera, fue difícil la consolidación de los proyectos iniciados y de nuevo casi todas las plazas ganadas acabaron en manos granadinas.

Esperamos, en fin, con estas líneas, que no tenían más propósito que el de realizar una serie de reflexiones a la luz de tres documentos inéditos conservados en el Archivo de la Catedral de Murcia, y que constituyen nuestra principal apor- 
tación, haber contribuido a aclarar mejor un periodo menos conocido de la historia granadina que los años anteriores y posteriores.

\section{ApÉNDICE DOCUMENTAL}

\section{$-1-$}

1434, noviembre, 23, martes. Huéscar (Granada). - 1434, noviembre, 25, jueves. Huéscar (Granada).

Martín Carrión, clérigo beneficiado de la iglesia de San Bartolomé de Murcia, en nombre del obispo, deán y cabildo de la Iglesia de Cartagena, toma posesión de la casa de oración de Huéscar y sus anexos de Orce, Galera y Castella (Castilléjar) cuando fueran cristianas, mediante la presentación de una carta de poder del obispo fray Diego de Bedán, dada en Murcia, a 17 de noviembre de 1434, que se inserta, y consagra las iglesias y cementerios; entrando en conflicto con Alfonso Gómez, vecino de Alcaraz, que alega derechos en nombre de la Iglesia de Toledo.

A: ACM, leg. 208, exp. 1150. Testimonio notarial. Papel. 7 ff. ${ }^{74} 215$ x 145 mm. (180 x $111 \mathrm{~mm}$ ). Buen estado de conservación, salvo alguna mancha de tarquín y de agentes biológicos. Tinta ocre. Escritura gótica cursiva documental denominada "cortesana". Presenta la firma y rúbrica del escribano Juan Rodríguez al final de cada folio. En el f. $7 \mathrm{r}$ presenta signo notarial de dicho escribano, en módulo pequeño y a la derecha, formado por cruz aspada o de San Andrés enmarcada en doble cartela acabada en espirales en sus vértices y a cuyos lados se sitúan cuatro pirámides.

C: ACM, leg. 208, exp. 1150. Testimonio notarial. Papel. 5 ff. $^{75} 215$ x 145 mm. (180 x $111 \mathrm{~mm}$ ). Regular estado de conservación, con roturas del folio por comedura de roedores en el margen superior izquierdo, superior derecho e inferior derecho que, en algunas ocasiones afectan al texto. Tinta ocre oscura. Escritura gótica precortesana con algunos caracteres propios de la cortesana.

\section{Transcripción del documento original (A):}

\section{$1 \mathbf{r}$}

En la villa de Vesca, martes, veynte e tres días del mes de nouienbre, anno del nasçimiento del Nuestro Saluador Ihesuchristo de mill e quatroçientos e treynta e quatro annos. Este día, en la casa de oraçión de la dicha villa, estando ende el honrrado cauallero Rodrigo Manrrique, comendador de Segura, e otros caualleros e otros munchos omes, en presençia

74. El orden de encuadernación es el siguiente: primero aparece la copia simple en letra precortesana y tinta ocre oscura y más adelante el original en letra cortesana y tinta ocre clara, con dos portadillas en letra bastarda del siglo XVII o XVIII desde donde se empieza a contar en la foliación, que aquí no respetamos.

75. Como hemos señalado anteriormente, en la foliación no respetamos la existente, donde se cuentan también las dos portadillas con letra bastarda del siglo XVII o XVIII, sino que comenzamos a contar desde el primer folio en precortesana. 
de mí, Juan Rodrígues de Segura, escriuano de nuestro sennor el rey e su notario público en la su Corte e en todos los sus regnos, e de los testigos de yuso escriptos, podía ser a la ora de la prima del día poco más o menos tienpo, paresçió ende presente vn ome clérigo que se dixo por nonbre Martín Carrión, clérigo benefiçiado que se dixo en la yglesia de Sant Bartolomé de la çibdat de Murçia, en bos e en nonbre del muy //1v reuerendo yn Christo padre e sennor don frey Diego, obispo de Cartajenia ${ }^{76}$, segúnd paresçía por vn $a$ carta de poder que a mí, el dicho escriuano dio, firmada del dicho obispo e sellada con su sello, la qual me requerió que leyese antel dicho comendador e caualleros e los otros que ende estauan, el tenor de la qual es este que se sygue e dise en esta guisa ${ }^{77}$ :

"Don frey Diego, por la graçia de Dios e de la Santa Yglesia de Roma, obispo de Cartajenia, a vos, Diego Martínes de Ruuielos, nuestro arçipreste en la villa de Lorca, e a Juan Sánches de Clares, vicario de Segura, et a Martín Carrión, benefiçiado en Sant Bartolomé de la çibdat de Murçia, e a cada vno de vos in solidum, salud e bendiçión. Sepades que nos somos informado que la villa de Vesca, que era de moros enemigos de la fe, por la graçia de Dios $/ /^{2 r}$ es ganada e redusida en poder de christianos, la qual villa es de nuestro obispado e dióçesis de Cartajenia. Et por quanto por los semejantes fechos a Dios deuen ser dadas munchas graçias e faser sacrifiçios a seruiçio, loor e alabança suya e por consolaçión de los caualleros e pueblos christianos que ay son e serán, es nesçesario de remediar cómo en la dicha villa se digan misas et se administren todos los otros eclesyásticos sacramentos et se prouea de lugar o lugares onestos para que las sobredichas cosas se fagan como cunple a seruiçio de Dios. E por quanto a nos pertenesçe asy como a prelado de proueer en lo sobredicho, confiando de la prudençia e susfiçençia de vos e de cada vno de vos, por la presente vos cometemos et damos nuestro poder conplido e liçençia para que vades a la dicha villa et podades edeficar e yrigir e costruyr yglesia o yglesias o asygnar lugar o lugares que a vos o a cada et a cada vno de //2v vos paresçiere ser líçitos e onestos; e que para en ellos e cada vno dellos podades desir e çelebrar misa e misas e mandas e cometer a otros que las çelebren; e administrar todos los sacramentos, et para oyr de confesyones e absoluer et cometer a otros que oyan e absueluan. Para lo qual a vos e a cada vno de vos e aquel e aquellos a quien lo cometiéredes, damos e otorgamos los nuestros casos ponteficales, exçeptos aquellos que a nos de derecho son reseruados, los quales aqui auemos por espresos e nonbrados; en testimonio de lo qual vos mandamos dar e librar esta nuestra carta, firmada de nuestro nonbre e sellada en las espaldas con nuestro sello pontifical. Dada en la muy noble çibdat de Murçia, miércoles dies e syete días del mes de nouienbre, anno Domini millesimo cuadracentesimo triçesymo quarto. Episcopus Cartaginensis. Et firmada de otro nonbre que desía «Robertus, notarius appostolicus»”.

La qual dicha carta de poder $/ /^{3 \mathrm{r}}$ del dicho sennor obispo asy leyda e publicada por mí, el dicho escriuano, luego el dicho Martín Carrión, en nonbre del dicho sennor obispo e del cabildo de Cartajenia, tomó vn libro misal e vnas vestimentas e cális que tenía puestas ençema del altar e dixo en $e$ dicho nonbre del dicho sennor obispo e cabilldo que tomau $a$

76. Se refiere indiscutiblemente al franciscano fray Diego de Bedán, que ocupó la sede cartaginense entre 1415 y 1442 aproximadamente, aunque hay dudas sobre sus años finales. Vid. D. Carbajo López. "Don Fr. Diego de Babán o Bedán, duodécimo obispo de Cartagena (1415-1442)", Murgetana, 60 (1980), pp. 109-136.

77. En el texto va seguida. La entresacamos aquí así por claridad. 
e tomó posysyón de aquella casa de oraçión para yglesia, con todos derechos et inuençiones e libertades pertenesçentes al dicho sennor obispo e cabildo. E otrosy dixo en $e$ d dicho nonbre que tomaua e tomó desde agora posysyón e tenençia en los lugares de Orçe e Galera e Castella, con todos sus derechos pertenesçentes al dicho sennor obispo e cabildo de la Yglesia de Cartajenia, para cada e quando a Dios pluguiese que fuesen de christianos, que confiau $a$ en Dios que sería çedo ${ }^{78}$. Et desto en como pasó, el dicho Martín Carrión dixo que pedía a mí, dicho escriuano, que ge lo diese asy por testimonio. Et luego esto fecho, paresçió y presente vn ome que se dixo Alfon Gómes, vesino de Alcaras, en bos e en nonbre $/^{/ 3 v}$ e como procurador que se dixo ser de la Yglesia de Toledo, et dixo que él, en nonbre de la dicha Yglesia de Toledo, que reuocaua e reuocó lo quel dicho Martín Carrión desía e la posysyón que toma, por quanto dixo que él auía tomado e tenía la dicha posysyón tomada en nonbre de la dicha Yglesia de Toledo; la qual dixo que aúa tomado con vn libro misal que auía fallado en $e$ altar de la dicha yglesia e por ante testigos, por quanto dixo que non auía podido auer escriuano para tomar testimonio. E que pues él auía tomado e tenía la dicha posysyón primero, que reuocau $a$ e reuocó todo lo quel dicho Martín Carrión fasía e desía, e que lo pedía asy por testimonio. Et luego, el dicho Martín Carrión dixo que él, en el dicho nonbre del dicho sennor obispo e cabildo, que reuocau $a$ lo quel dicho Alfon Gomes desía e que en ello non consentía: lo primero porque le negau $a$ e negó quél fuese parte por la dicha Yglesia de Toledo para tomar tal posysyón; et otrosy que negau a e negó que la //4r Ique la/ dicha Yglesia de Toledo ouiese jurediçión alguna en la dicha Vesca et lugares por él çerteficados; lo otro por $<$ quanto $>$ dixo que él auía tomado e tenía la posysyón e tenençia de la dicha casa de oraçión antes, que non el dicho Alfon Gomes, et aquel misal que él auía tomado del altar en sennal de tenençia e posysyón por el dicho su parte con vestimenta, e ara, e los otros onramentos ${ }^{79}$ pertenesçientes para desir misa por ante testigos era suyo e lo él auía puesto ally; e que non enbargante todo lo por el dicho Alfon Gomes dicho, que lugar non auía, que afirmándose en la posysyón por él tomada en nonbre del dicho sennor obispo e cabildo que él, en contynuando su posysyón, que se reuestía e revistió para desir misa; la qual dixo antel dicho comendador de Segura e otros caualleros e otras munchas gentes e por presençia de mí, el dicho escriuano. E luego asy dicha la misa, el dicho Martín Carrión tomó vna crus e dixo dos responsos cantados sobre las fuesas de aquellos christianos //4v que ally estauan enterrados que murieron al tomar de la dicha villa. E asy dichos los dichos responsos, el dicho Martín Carrión dixo al dicho comendador que ponía nonbre aquella yglesia Santa María enmedio de la dicha yglesia, et que edeficaua e edificó a la parte derecha, a do se dise la Pístola ${ }^{80}$, vn altar en el qual edeficó la vocaçión de sennora Santa Catalina, et a la otra parte del Euangelio que edificau $a$ e edificó vn altar de inuocaçión e a onor e reuerençia del bienauenturado sennor Sant Leonardo, porque en tal día se entró en la dicha villa de Vesca; e dixo más que edificau $a$ e edificó lugar do estouiese la pilla del bavtisar, a la parte ysquierda como entra omne en la dicha yglesia. Et otrosy dixo que edificaua e edificó la otra casa de oraçión que está en la dicha villa de Vesca, a la parte de la puerta Castril para yglesia e púsole nonbre a reuerençia de sennor Santiago e a la man ysquierda vn altar a reuerençia de sennor Sant Martín, por quanto en tal día se tomó //5r el castillo de la dicha villa; e de todo esto en como pasó dixo que pedía testimonio. Et luego el dicho Alfon Gómes dixo que todo lo reuocau $a$. E luego el dicho Rodrigo Manrrique, comendador de Segura, dixo que a él le plasía e plugo de todo lo fecho e nonbrado por el dicho Martín

78. Cedo (del lat. cito, pronto). 1. adv. t. desus. Luego, presto, al instante. U. en el norte de España (Diccionario de la Lengua Española, 22ª ed., 2001, en línea).

79. Sic.

80. Por Epístola (la parte de la Epístola en un templo). 
Carrión, en nonbre del dicho sennor obispo, protestando que todos los derechos a la Orden de Santiago pertenesçientes en la dicha Vesca le quedasen a saluo. Testigos que a esto todo fueron presentes: Garçía Lópes de Cárdenas, comendador de Carauaca; e Pedro de Soto, comendador de Aledo; e Ferrando de Áuila, comendador de Veas; e Juan de Claramontes, e Martín Alfon de Funes, e Ferrando Calderón, vesinos de Alcaras, e otros muchos omes.

Et luego, en este dicho día e mes e anno susodicho, el dicho Martín Carrión dixo que, por virtud del poder quél tenía del dicho sennor obispo, que ponía e puso e tomó por conpanero, continuando su posysyón, a Alfon Gutiérres de Escobar, //5v clérigo e cura de las Vayonas, lugar de la encomienda de Segura, que presente estaua, al qual dixo que en el dicho nonbre que daua e dio poder conplido para poder desir misa e para confesar e absoluer e faser todos los otros sacramentos a la dicha yglesia pertenesçientes. Et luego, el dicho Alfonso Gómes dixo que lo contradesía e que él, en nonbre de la Yglesia de Toledo, que lo ponía e puso al dicho Alfon Gutiérres en posysyón de la dicha yglesia e por clérigo della, e que lo pedía asy por testimonio. Et luego, el dicho Martín Carrión dixo que, afirmándose en la su posysyón por él tomada, en nonbre del dicho su parte, que contradesía todo lo por el dicho Alfonso Gómes fecho e dicho, e que pedía asy testimonio. Testigos que a esto fueron presentes: Pedro de Soto, e Juan de Taminio, e Alfon de Robres, vesino de Carauaca; e Juan de Moldes, vesino de Veas; e Pero Gonsales, baruero; vesino de Segura, e otros.

Et después de lo susodicho, en la dicha yglesia de Santa María, miércoles veynte e quatro días del dicho //6r mes de nouienbre, anno susodicho, el dicho Martín Carrión dixo misa en afirmando su posysyón. E otrosy dixo responsos ençima de las sepolturas de los dichos finados e dio su absoluiçión e bendixo agua bendita. E de todo tomó testimonio. Testigos los susodichos e otros.

Et después de lo susodicho, en la dicha yglesia de Santa María, jueues veynte e çinco días del dicho mes de nouienbre, anno susodicho de mill e quatroçientos e treynta e quatro annos, el dicho Martín Carrión dixo misa en la dicha yglesia e dio el cuerpo de Nuestro Sennor Dios a Rodrigo de Eredia, vesino de Veas, e a Juan Sanches Ferrero, vesino de Segura. Et asy dicha la dicha misa e dado el dicho sacramento, el dicho Martín Carrión en el dicho nonbre, dixo al dicho Rodrigo Manrrique, comendador de Segura, que en el dicho nonbre quería çerteficar en las dichas yglesias çimenterios para las dichas yglesias, et dixo que al presente que çerteficaua e çerteficó el corral de la dicha yglesia de Santa Maria e en la dicha yglesia de Santiago //6v dos corrales que están a las espaldas de la dicha yglesia a man ysquierda por çimenterios de las dichas yglesias. E el dicho comendador dixo que por virtud de la Santa Madre Yglesia, que a él plasía de todo lo çerteficado por él que fuesen yglesias e çementerios. Et luego el dicho Martín Carrión dixo que por que qualquier clérigo que aquí estouiese en las dichas yglesias por el dicho sennor obispo touiese casa de la yglesia de Santa María para do estouiese, que le pedía por merçed que le fisiese merçed de vnas casas que estauan cabo la dicha yglesia de Santa María, entre el adarue de la dicha yglesia. Et el dicho comendador dixo que esto era a faser al rey nuestro sennor, pero que en quanto a él fasía que él fasía graçia de las dichas casas por el dicho Martín Carrion çerteficadas para la dicha yglesia; e que sy al dicho sennor rey pluguiese dello, que él desde agora la daua e dio, e el dicho Martín Carrión dixo que lo resçebía e que de todo pedía testimonio. Testygos los susodichos e otros. Va escripto entre renglones o dis "quanto", no le enpesca. Et yo Juan $/ / 7 \mathrm{rr}$ Rodrígues de Segura, escriuano de nuestro sennor el rey et su notario público en la su Corte e en todos los sus regnos, que este instrumento escreuí e a todo lo en él contenido, en vno con los dichos testigos presente fuy; el qual va escripto en estas syete fojas de papel de quarto de pligo con esta en que va mío sygno, e en fyn de cada vna foja de amas partes firmado de mi nonbre e ençima fechas vnas rayas tynta; e por ende, en testymonio de verdad, fis aquí este mío acostunbrado syg(signo)no. Juan Rodrígues (Rúbrica) // 
[ca. 1436], [s.m.], [s.d.]. [iMurcia?].

Informe sobre la forma en que se ha de llevar a cabo la organización administrativa de los lugares del obispado de Cartagena en el Reino de Granada.

C: ACM, leg. 208, exp. 1151, fol. 14. Informe. Papel. 1 fol. 310 x 218 mm. (280 x 194 $\mathrm{mm})$. Buen estado de conservación. Tinta ocre. Escritura gótica cursiva documental denominada "cortesana".

Cit. y pub. (en parte): M. Rodríguez Llopis e I. García Díaz. Iglesia y sociedad feudal. El cabildo de la Catedral de Murcia en la Baja Edad Media, Murcia, Universidad de Murcia, 1994, p. 23, nota 5 y p. 24 , nota 7.

$$
\text { (Cruz) + }
$$

Los frutos deçimales de cada vna eglesia deste obispado de Cartajena se parten en esta manera: facense tres partes: la vna lieuan las eglesias o eglesia e las terçias del rey, la otra terçia parte lieua el obispo e cabildo, e la otra terçia parte lieuan los clérigos benefiçiados e la terçia parte lieua el préstamo.

En la villa de Huesca puede aver dos benefiçiados, ${ }^{81}$ vno en Santiago, que es en la $\backslash$ la/ puerta de Baça; e el otro en Santa Marya, que es en la plaça, e los dos préstamos que sean anexos a la dinidad que se fará en Husca, con más vna casa e un forno e heredamiento, con más la judicatura de Huesca, Orçe, Galera, Cúllar, e Castelleja, e los Felices el Blanco e el Ruuio, e Tirieça e Xiquena, en que la tal dinidad a su vícaria de Husca judgue todas las cosas, exçepto benefiçios e matrimoniles, e que las apelaçiones vayan al obispo de Cartajena, según los otros vicarios e arciprestes del dicho obispo de Cartajena.

Iten que en Bera aya tres beneficios, en la eglesia mayor dos e otro en otra, que lieuen préstamos de ally e de Moxácar, $<$ Oria e Cantoria $>82$, e las Cueuas, Huerca, Teresa e Cabrera son anexos a la dinidad que se fará, con más vna casa, forno e heredamiento, e más la judicatura de la dicha çibdad e de Moxácar e las Cueuas, Huerca, Teresa e Cabrera, con todos los otros logares del Val de Purchena que son del dicho obispado de Cartajena. E el que en Muxácar aya dos beneficios, otro en Cantoria e otro en Oria e cada lugar, ecétera. //

$-3-$

[ca. 1445], diciembre, 15. Huéscar (Granada).

El concejo de Huéscar se dirige al deán y cabildo de la Iglesia de Cartagena informándoles de la difícil situación de la villa, a punto de perderse para los moros por falta de apoyo real y por despoblación; y solicitando las rentas y diezmos del obispado de ese año para sostener el pago a los encargados de los turnos de ronda y vigilancia.

81. Tachado, a continuación, "en".

82. Sobrepuesto sobre "Muxacar" (tachado). 
A: ACM, leg. 208, exp. 1150, f. $15 .^{83}$ Súplica. Papel. 1 f. 225 x 200 mm. $(130$ x 170 $\mathrm{mm}$ ). Buen estado de conservación. Tinta ocre. Escritura gótica cursiva documental denominada "cortesana".

Sennores deán e cabyldo de la Yglesia de Cartajena ${ }^{84}$. El conçejo, alcayde, alcaldes, alguasil, regidores, caualleros, escuderos, ofiçiales e omes buenos de la villa de Huéscar; nos vos recomendamos ${ }^{85}$ con voluntad presta de faser todas las cosas que onor vuestro sean. Sennores, a vuestra merçed fasemos saber que por nuestros pecados esta villa está muy aparejado su perdymiento, a la qual plega Nuestro Sennor reparar e defender e guardar para la fe christiana: lo vno por el rey nuestro sennor no la mandar proueer segúnd cunple a seruiçio de Dios e suyo (esto creemos que lo causa los muchos trabajos suyos); lo otro, veyendo los vesinos della las malas prouisiones, son ydos muchos e vanse de cada día, lo qual bien creemos que vuestra merçed lo sabrá más largamente por las nueuas que de acá incurrirán allá. Por ende, sennores, a vuestra merçed suplycamos que por seruiçio de Dios vos adolescades desta \desta/ dicha villa e acatando quánto deseruiçio sería de Dios perderse; de nos acorrer con vuestra lymosna para ayuda ${ }^{86}$ a rondas e velas, en espeçial con la parte que a vuestra merçed pertenesçe de las rentas e diesmos desta dicha villa este anno, que ello es asaz poco, e a esta dicha villa fasérsele ha algo; que su fecho non está syno como el que dise ${ }^{87}$ "sácame deste barranco, degüéllame ${ }^{88}$ en $e$ l otro". En esto, sennores, vuestra merçed fará seruiçio a Dios e a esta dicha villa mucha merçed. E sennores, Dios que es poderoso vos aya en su santa guarda. De Guéscar, a los quinse de desienbre.

(Rúbricas autógrafas seguidas): (Rúbrica) Áluaro de Madrid (Rúbrica) / (Rúbrica) Ruy Ferrándes, regidor (Rúbrica) / (Rúbrica) Áluaro de Santacrus (Rúbrica) / (Rúbrica) Gonçalo Ferrándes, regidor (Rúbrica)

(A la izquierda): (Rúbrica) Juan Matheos, jurado (Rúbrica) //

83. No seguimos la foliación existente. Es el folio 15 si contamos desde el principio sin incluir portadilla, pero el f. 2 (o pieza 2) en la numeración existente.

84. Pese a que la dirección queda clara aquí, en la parte trasera de la carta se lee "Al muy reverendo sennor el sennor maestrescuela de Cartajena", probablemente por tener la función de canciller del cabildo. El hecho de que no se mencione al obispo en la dirección nos hace pensar que la sede estaba vacante aún tras el traslado de Diego de Bedán a Plasencia; no habiendo sido nombrado o no estando aún reconocida la autoridad de su sobrino Diego de Comontes, que no lo sería hasta 1446 en buena medida por la oposición del concejo de Murcia, dominado por Alonso Fajardo, debido a su apoyo al bando del adelantado don Pedro en la guerra civil murciana. J. Torres Fontes y Á. L. Molina Molina. Introducción, al Fundamento de la Santa Iglesia..., pp. 12-13.

85. Sic. Por encomendamos.

86. Tachada, a continuación, "s".

87. Tachada, a continuación, "a".

88. Como es de suponer, no existe la diéresis en el original. 


\section{BIBLIOGRAFÍA}

Alcántara Valle, José María. "Nobleza y señoríos en el reino de Granada durante el reinado de Alfonso X. Aproximación a su estudio", Vínculos de historia, 2 (2013), pp. 207-232.

Arcas Campoy, María. "Cadíes y alcaides de la frontera oriental nazarí (s. XV)", al-Qantara, XX-2 (1999), pp. 487-501.

Calero Palacios, María del Carmen y Peinado Santaella, Rafael Gerardo. "Fuentes para el estudio de la nobleza y los señoríos del reino de Granada: el inventario del archivo del Marquesado de Campotéjar (1682)", Revista del Centro de Estudios Históricos de Granada y su Reino, Segunda época, 1, 1987, pp. 239260.

Carbajo López, Deobato. “Don Fr. Diego de Babán o Bedán, duodécimo obispo de Cartagena (1415-1442)”, Murgetana, 60 (1980), pp. 109-136.

Carriazo Arroquia, Juan de Mata. Crónica del Halconero de Juan II, de Pedro Carrillo de Huete. Madrid, CSIC, 1946.

Driss, Abdelghaffar ben. "La frontera granadino-castellana en la primera mitad del siglo XV”, en I Estudios de Frontera. Alcalá la Real y el Arcipreste de Hita, Jaén, 1997, pp. 41-48.

Espinar Moreno, Manuel y Grima Cervantes, Juan. "Un personaje almeriense en las crónicas musulmanas y cristianas. El infante Cidi Yahya Alnayar (1435?1506): su papel en la Guerra de Granada", Boletín del Instituto de Estudios Almerienses, 7 (1987), pp. 57-83.

—. "Testamento y muerte de don Pedro de Granada", Mayurqa, 22 (1989), pp. 239-254.

Estal, José María del. El Reino de Murcia bajo Aragón, Alicante, 1985, 1990 y 1999.

Ferrer i Mallol, María Teresa. La frontera amb l'Islam en el segle XIV. Cristians $i$ sarraïns al País Valencià, Barcelona, CSIC, 1988.

-. Organització i defensa d'un territorio fronterer. La Governació d'Oriola en el segle XIV, Barcelona, CSIC, 1990.

García Fernández, Manuel. "La frontera de Granada a mediados del siglo XIV", Revista de Estudios Andaluces, 9 (1985), pp. 69-86.

—. "Sobre la alteridad en la frontera de Granada. Una aproximación al análisis de la guerra y la paz, siglos XIII-XV", Revista da Faculdade de Letras. História, III Serie, 6 (2005), pp. 213-235.

González Jiménez, M. “La conquista y formación de Andalucía”, en M. González Jiménez y J. E. López de Coca Castañer (dirs.). Historia de Andalucía, t. IV, Barcelona, 2006, pp. 12-47.

—. La Repoblación del Reino de Sevilla en el siglo XIII, Granada, 2008.

Jiménez Alcázar, Juan Francisco. Huércal y Overa. De enclaves nazaries a villas cristianas (1244-1571). Huércal-Overa, 1996.

- y Ortuño Molina, Jorge. "El privilegio de repoblación de Xiquena (s. XV). Un proyecto frustado", Clavis, 4-5 (2008), pp. 33-51. 
-. "Et por estar esta tierra en frontera de moros: sociedad y territorio en la frontera de Granada (siglos XIV-XV)", en De la Iglesia Duarte, José Ignacio (Coord.), Monasterios, espacio y sociedad en la España cristiana medieval: XX Semana de Estudios Medievales. Nájera, del 3 al 7 de agosto de 2009, Logroño, 2010, pp. 353-394.

—. "Relaciones interterritoriales en el Sureste de la Península Ibérica durante la Baja Edad Media: cartas, mensajeros y ciudades en la frontera de Granada", Anuario de Estudios Medievales, 40/2, (julio-diciembre de 2010), pp. 565-602.

- " "Gobernar fronteras: poderes locales, dominio territorial y control central en la Castilla meridional (ss. XIII-XVI)", Edad Media. Revista de Historia, 14 (2013), pp. 129-148.

Jover Carrión, María de los Ángeles. Juan Torres Fontes y el Archivo Municipal. Murcia, 1988.

López de Coca Castañer, José Enrique. "Castilla, Granada y la tregua de 1443", en V. Á. Álvarez Palenzuela, M. Á. Ladero Quesada, J. Valdeón Baruque (Coords). Estudios de Historia Medieval. Homenaje a Luis Suárez, Valladolid, 1991, pp. 301-313.

—. "Fernando Álvarez de Toledo, capitán de la frontera de Jaén (1434-1437)", Anuario de Estudios Medievales, 33/2 (2003), pp. 643-666. http://dx.doi. org/10.3989/aem.2003.v33.i2.215

Malpica Cuello, Antonio. "Las fortificaciones de la frontera nazarí-castellana, PH. Boletín del Instituto Andaluz del Patrimonio Histórico, año 9, 36 (2001), pp. 216-224.

-. "Un asentamiento fortificado en la frontera nazarí-castellana: Castril de la Peña", Studia historica. Historia medieval, 24 (2006), pp. 197-225.

—. "El agua en la agricultura. Agroecosistema y ecosistemas en la economía rural andalusí", Vínculos de Historia, 1 (2012), pp. 31-44.

Martínez Martínez, María. "La obra del medievalista murciano Juan Torres Fontes", en Homenaje al Profesor Juan Torres Fontes, Murcia, 1987, pp. 1017-1030.

Molina Molina, Ángel Luis. Documentos de Pedro I, CODOM, VII. Murcia, 1978.

—. "Juan Torres Fontes. (Notas para su biobibliografía)", Revista Electrónica de Estudios Filológicos, 15 (2008), en línea.

-. Murcia medieval (siglos VIII-XV), Murcia, 2014.

Pascual Martínez, Lope. Documentos de Enrique II, CODOM, VIII. Murcia, 1983.

Peláez Rovira, Antonio. El emirato nazarí de Granada en el siglo XV. Dinámica política y fundamentos sociales de un Estado andalusí. Granada, 2009.

Pérez de Guzmán, Fernán y Galíndez de Carvajal, Lorenzo. Crónica del señor Rey don Juan, segundo de este nombre en Castilla y en León. Valencia, 1779. En línea.

Reinaldos Miñarro, Diego Antonio. "A frontier cartulary. The Lorca's council (Murcia, Spain) cartulary in the years 1463 and 1464 as a source to study the frontier relationships between Murcia and Granada's Kingdoms", The Urban late Medieval Society. Actas del II IMM Lleida 2012, Turnhout (en prensa). 
Rodríguez Llopis, Miguel. Señoríos y feudalismo en el Reino de Murcia: los dominios de la Orden de Santiago entre 1440 y 1515. Murcia, 1986.

- y García Díaz, Isabel. Iglesia y sociedad feudal. El cabildo de la Catedral de Murcia en la Baja Edad Media. Murcia, 1994.

Rodríguez Molina, José. "La frontera de Granada, siglos XIII-XV”, en I Jornadas de Estudios de Frontera. Alcalá la Real y el Arcipreste de Hita, Jaén, 1997, pp. 503-560.

Salicrú i Lluch, Roser. El sultanat de Granada i la Corona d'Aragó, 1410-1458, Barcelona, 1998.

Suárez Fernández, Luis. Nobleza y monarquía: entendimiento y rivalidad. El proceso de la construcción de la Corona española, Madrid, 2003.

Torreblanca López, Agustín. "Una expedición de Rodrigo Manrique contra la frontera de Granada (junio de 1435)", en VV. AA. Homenaje al profesor Juan Torres Fontes, Murcia, 1987, pp. 1673-1680.

Torres Fontes, Juan. Don Pedro Fajardo, Adelantado Mayor del Reino de Murcia. Madrid, CSIC, 1953.

—. Xiquena, castillo de la frontera. Murcia, 2a ed., 1960 (reimp. 2007).

- Documentos del siglo XIII. CODOM, II, Murcia, 1969.

—. Documentos de Sancho IV. CODOM, IV, Murcia, 1977.

—. "Dualidad fronteriza: guerra y paz", en Pedro SEGURA ARTERO (Coord.), Actas del Congreso la Frontera Oriental Nazarí como Sujeto Histórico (S.XIIIXVI): Lorca-Vera, 22 a 24 de noviembre de 1994. Almería, 1997, pp. 63-78.

-. Fajardo el Bravo. Murcia, $3^{\mathrm{a}}$ ed., 2001.

-. La frontera murciano-granadina, Murcia, 2003.

—. "La muerte de Alonso Fajardo", en La frontera murciano-granadina, pp. 204205. Publicado originalmente en AEM, 4 (1967), pp. 409-418.

-. Instituciones y sociedad en la frontera murciano-granadina. Murcia, 2004.

-. "El señorío del Valle del Almanzora en la Edad Media", en Instituciones y sociedad..., op. cit., pp. 365-383. Pub. originalmente en Roel, 2 (1981), pp. 17-26.

—. "Alonso Yáñez Fajardo y su señorío de Vélez Rubio, Vélez Blanco y Orce”, en Instituciones y sociedad en la frontera murciano-granadina. op. cit., pp. 417433. Publicado originalmente en Scripta. Estudios en homenaje a Élida García García, Oviedo, 1998, pp. 603-610.

—. "Conquista y pérdida de Huéscar en el reinado de Juan II de Castilla", en Instituciones y sociedad..., op. cit., pp. 435-462. Publicado originalmente en Murgetana, 84 (1992), pp. 81-99.

- "Conquista castellana y pérdida de Albox en el reinado de Juan II (14361445)”, en Instituciones y sociedad..., op. cit., pp. 463-474. Pub. originalmente en Roel. Cuadernos de Civilización de la Cuenca del Almanzora, 1, 1980, pp. 35-41.

- "Reconquista y repoblación del Reino de Murcia", Actas del Coloquio de la V Asmblea General de la Sociedad Española de Estudios Medievales, Zaragoza, 1991, pp. 249-272. 
- y Molina Molina, Á. L. (eds.). Fundamento de la Santa Iglesia y de toda la Diócesis de Carthagena, escrito y ordenado por el Ilustrísimo señor don Diego de Comontes. estudio y edición facsímil de la de 1756, Murcia, 2009.

Veas Arteseros, Francisco de Asís. "Lorca, base militar murciana frente a Granada en el reinado de Juan II (1406-1454)", Miscelánea Medieval Murciana, 5 (1980), pp. 159-188.

-. "El Obispado de Cartagena. Una frontera político-religiosa", Murgetana, $\mathrm{n}^{\circ}$ 114 (2006), pp. 19-51.

—. "In memoriam. Prof. D. Juan Torres Fontes (1919-2013)", AEM, 43/2 (juliodiciembre de 2013), pp. 943-948.

VV.AA., El otro lado. Asentamientos rurales andalusies en la frontera oriental nazarí. Murcia, 2009.

Fecha de recepción del artículo: abril de 2014

Fecha de aceptación y versión final: junio de 2014 